\title{
Effects of Practice on Interference From an Auditory Task While Driving: A Simulation Study
}


This publication is distributed by the U.S. Department of Transportation, National Highway Traffic Safety Administration, in the interest of information exchange. The opinions, findings and conclusions expressed in this publication are those of the author(s) and not necessarily those of the Department of Transportation or the National Highway Traffic Safety Administration. The United States Government assumes no liability for its content or use thereof. If trade or manufacturer's names or products are mentioned, it is because they are considered essential to the object of the publication and should not be construed as an endorsement. The United States Government does not endorse products or manufacturers. 
Technical Report Documentation Page

\begin{tabular}{|c|c|c|c|c|}
\hline $\begin{array}{l}\text { 1. Report No. } \\
\text { DOT HS } 809826\end{array}$ & \multicolumn{2}{|c|}{ 2. Government Accession No. } & \multicolumn{2}{|c|}{ 3. Recipient's Catalog No. } \\
\hline \multicolumn{3}{|c|}{$\begin{array}{l}\text { 4. Title and Subtitle } \\
\text { Effects of Practice on Interference From an Auditory Task While Driving: } \\
\text { A Simulation Study }\end{array}$} & \multicolumn{2}{|c|}{$\begin{array}{l}\text { 5. Report Date } \\
\text { October } 2004\end{array}$} \\
\hline \multicolumn{3}{|c|}{$\begin{array}{l}\text { 7. Author(s) } \\
\text { David Shinar and Noam Tractinsky }\end{array}$} & \multicolumn{2}{|c|}{ 8. Performing Organization Report No. } \\
\hline & \multicolumn{2}{|c|}{ 10. Work Unit No. (TRAIS) } \\
\hline \multicolumn{3}{|c|}{$\begin{array}{l}\text { David Shinar, Ph.D. } \\
8323 \text { Still Spring Ct. Bethesda, MD } 20817\end{array}$} & \multicolumn{2}{|c|}{ 11. Contract or Grant No. } \\
\hline \multicolumn{3}{|c|}{$\begin{array}{l}\text { 12. Sponsoring Agency Name and Address } \\
\text { National Highway Traffic Safety Administration } \\
\text { Office of Research and Technology } \\
4007^{\text {th }} \text { Street, SW. }\end{array}$} & \multicolumn{2}{|c|}{$\begin{array}{l}\text { 13. Type of Report and Period Covered } \\
\text { Final Report }\end{array}$} \\
\hline \multicolumn{3}{|c|}{\begin{tabular}{l|l} 
Washington, DC 20590 & \\
\end{tabular}} & \multicolumn{2}{|c|}{ 14. Sponsoring Agency Code } \\
\hline \multicolumn{5}{|c|}{$\begin{array}{l}\text { 15. Supplementary Notes } \\
\text { Richard Compton was the Contracting Officer's Technical Representative for this project }\end{array}$} \\
\hline \multicolumn{5}{|c|}{$\begin{array}{l}\text { 16. Abstract } \\
\text { Experimental research on the effects of cellular phone conversations on driving indicates that the phone task } \\
\text { interferes with many driving-related functions, especially with older drivers. Limitations of past research have } \\
\text { been that (1) the dual task conditions were not repeated in order to test for learning, (2) the "phone tasks" } \\
\text { were not representative of real conversations, and (3) most often both the driving task and the phone task } \\
\text { were experimenter-paced. In the real-driving environment, drivers learn to time-share various tasks, they can } \\
\text { pace their driving to accommodate the demands of the phone conversation, and can even partially pace the } \\
\text { phone conversation to accommodate the driving demands. The present study was designed to better simulate } \\
\text { real driving conditions by providing a simulated driving task with repeated experiences of simulated driving } \\
\text { and talking and two different phone tasks with different proximities to real conversations. In the course of five } \\
\text { sessions of driving and using the phone, there was a learning effect on most of the driving measures. In } \\
\text { addition, the interference from the phone task on many of the driving tasks diminished over time as expected. } \\
\text { Finally, the interference effects were greater when the phone task was an artificial math operations task than } \\
\text { when it was an emotionally-involving conversation, when the driving demands were greater, and when the } \\
\text { drivers were older. Thus, the deleterious effects of conversing on the phone are very real initially, but may not } \\
\text { be as severe with continued practice at the dual task, especially for young or middle-age drivers. }\end{array}$} \\
\hline \multicolumn{2}{|c|}{$\begin{array}{l}\text { 17. Key Words } \\
\text { Driver distraction, cell phone and driving, age and } \\
\text { driving, practice and distraction. }\end{array}$} & \multicolumn{3}{|c|}{$\begin{array}{l}\text { 18. Distribution Statement } \\
\text { This document can be found on NHTSA's Web } \\
\text { site at www.nhtsa.dot.gov. It is also available } \\
\text { from the National Technical Information Service, } \\
\text { Springfield, VA (703-605-6000) }\end{array}$} \\
\hline $\begin{array}{l}\text { 19. Security Classif. (of this report) } \\
\text { Unclassified }\end{array}$ & 20. Sec & f. (of this page) & $\begin{array}{l}\text { 21. No. of Pages } \\
50\end{array}$ & 22. Price \\
\hline
\end{tabular}

Form DOT F 1700.7 (8-72) Reproduction of completed page authorized 


\section{INRODUCTION}

Innovative in-vehicle technologies are increasing the scope of activities drivers can perform while driving. They increase drivers' communication capabilities, and provide various safety benefits. One ubiquitous manifestation of the new technologies is the invehicle cellular phone and the use of portable cellular phones while driving. As the number of people with cell phones increases, so does the number of drivers who use invehicle cell phones. In a nationally representative telephone survey conducted by the National Highway Traffic Safety Administration (NHTSA) in April 2002, more than 60\% of the respondents said they have a cellular phone, and about $30 \%$ used the phone to make or receive calls while driving (Royal, 2003). This is a 10\% increase in the number of people using phones while driving, based on an NHTSA-sponsored observational survey conducted a year and a half earlier (Utter, 2001). ${ }^{1}$

Talking on the phone while driving is a distracting task, but it is not the only potentially distracting task observed on the road. The same NHTSA-sponsored survey revealed that talking or listening to someone on the phone is less frequent than talking to other passengers (81\% of respondents), changing radio stations, cassettes, or CDs (66\%), and eating or drinking (49\%) (Royal, 2003). Furthermore, the actual frequency of use, at least of hand-held phones, may not be that high. In one nationally representative observational study conducted in 2000 (Utter, 2001) at 690 controlled intersections, across all times, all locations, and all drivers, only $3.0 \%$ of the drivers were seen using a hand-held cell phone (however, this is most likely an underestimate of the true use of cell phones, because the frequency of drivers using hands-free phones could not be assessed).

From a cognitive, human-information-processing perspective, the use of the phone while driving constitutes a time-sharing situation in which driving is the primary task (hopefully) and talking on the phone is the secondary task. As such, the phone task can be distracting, disruptive to driving, and potentially dangerous. This is the general conclusion of NHTSA reviews of the literature in this area (Goodman, 1997; Goodman, Tijerina, Bents, and Wierwille, 1999). This general conclusion is supported by laboratory and driving simulation studies (McKnight and McKnight, 1993; Alm and Nilsson, 1993; Strayer and Johnston, 2001), closed-track road studies (Ishida and Matsuura, 2001; Hancock, Lesch, and Simmons, 2003), and open-road studies (Brown, Tickner, and Simmonds, 1969; Harbluk, Noy, and Eizenman, 2002). When the driving or driving-like tasks are sufficiently difficult, all these studies show some deterioration in these tasks when secondary cognitive perceptual-motor tasks must be performed in parallel to the driving task. In addition, two epidemiological studies have demonstrated an association between in-vehicle phone use and crashes (e.g., Redelmeier and Tibshirani, 1997; Laberge-Nadeau, Maag, at el., 2001).

A paradigm common to all the experimental studies that have been reviewed is that both the driving task and the distracting cell phone task are experimenter-paced (unless driving

\footnotetext{
${ }^{1}$ As these studies involved different methodologies and sampling plans (self-reports of use over time versus direct observations in specific locations), their results are not directly comparable.
} 
speed is one of the measures of driving performance), and the study compares the performance of one or more control conditions (no distraction or listening to music) with one or more distracting conditions (math operations, short-term memory tasks, conversations, message comprehension and recall, etc.) in a situation where each condition is presented only once, or for one block of trials.

However, these two common features - fixed paced tasks and one trial or block of trials in each condition - are not typical of driving in general nor of driving while performing other tasks in particular. Driving and conversing on the phone are both partially selfpaced tasks. Drivers can often adjust their speed to control the rate of information input, and they can often pause in the conversation or postpone a conversation when the driving task is too demanding. In addition, as in other tasks in life, performance improves with practice and feedback, so that the more practiced a task is, the more it (or parts of it) can be automated; consequently, more attentional capacity is left for other tasks. Thus, practice at a task can enable a person to time-share it effectively with other tasks. This has been repeatedly demonstrated in studies on perceptual-motor task performance and time-sharing of various tasks (e.g., Wickens and Hollands, 1999).

In driving, much of the experience-based improvement is based on subtle and gradual changes in information acquisition and processing. This has been demonstrated in changes in visual search (Mourant and Rockwell, 1972), and in the automation of shifting gears (Shinar, Meir, and Ben-Shoham, 1998). There is also evidence for the self-paced nature of driving, as a means of compensating for information overload or underload, and it comes from several studies of driving performance and behavior. Thus it has been demonstrated that drivers who are fatigued tend to speed up (to increase the rate of information input and thus reduce the boredom of the driving task) (Fuller, 1984). To counter overload from using the cell phone while driving, drivers often increase their safety margins by increasing headways to vehicles ahead (Brookhuis de Vries and Waard, 1991; Ishida and Matsuura, 2001), or by reducing their speed (Ishida and Matsuura, 2001; Waugh, Glumm, et al., 2000). Finally, when fatigued, driving performance can actually be aided by a "distracting" task such as a conversation (Drory, 1985), or a cognitively challenging game (Oron, Ronen, Shinar, and Cassuto, 2002).

In addition to pacing or modifying the driving, drivers can also pace the phone conversation. This was actually demonstrated in one study where driver response times to questions asked over the phone were delayed relative to responses made to the same question when the conversant was a passenger in the car, or when the questions were asked while the car was stationary (Waugh, Glumm, et al., 2000).

In terms of crash involvement, the actual contribution of engaging in a phone conversation is hard to assess, and has been estimated from as low as 10 fatalities per year to as high as a 1,000 (Hahn and Dudley, 2002). In a NHTSA-sponsored telephone survey of a nationally representative sample of drivers, Royal (2003) reports that $3.5 \%$ have had a crash within the past 5 years which they attributed to distraction (of any kind), and only $0.1 \%$ of the drivers (or $0.5 \%$ of those using cell phones while driving) attributed a crash to distraction from a cell phone. Royal concludes that based on driver perceptions, 
cell phones - at their current use levels - account for only $3 \%$ of all distracted-driving crashes. In terms of cost-benefit ratio, researchers from the Harvard Center for Risk Analysis concluded that a ban on the use of cell phones while driving would cost $\$ 700,000$ per quality-adjusted life-year saved (Lissy, Cohen, Park, and Graham, 2000), which is less cost-effective than many other approaches to saving lives. However, it is very possible that as the use of cell phones spreads to more drivers and to more and longer conversations, the actual crash risks due to phone distractions will increase as well. An interesting historical perspective is provided by Goodman (1997) who noted that in 1938 concerns similar to those that are raised now with respect to cell phones were raised with respect to allowing drivers to listen to the radio while driving. This perspective raises the issue of whether or not the introduction of new cognitive tasks to the driving situation necessarily impairs driving significantly, beyond the level that drivers are willing to tolerate, and if so under what conditions and for how long. Like other psychomotor skills, it is possible that the complex task of sharing the driving task with the listening/talking phone task can be improved with practice.

The objective of this research was to determine if there are practice-related improvements in the use of cell phones during a simulated driving task. This is the second study we have conducted on this issue. In the first study (Shinar, Tractinsky, and Compton, 2002), we examined the effects of practice on drivers' ability to combine a phone task and driving in a simulator. The drivers were all students with $5+$ years of driving experience. The participants drove an STI simulator either without a phone, with a hands-free phone, or with a hand-held phone. The distraction task was either a comprehension task in which drivers heard a short essay and were then questioned on it, a short-term memory-span task where the drivers heard a sequence of six 1-2 digit numbers and then were asked to state whether a seventh number was one of the six or not, and a math operations task where the drivers had to perform a string of operations on single-digit numbers. To assess the effects of practice, the drivers performed the driving task with the different distractions on five sessions over a period of two weeks. In general, performance on some of the driving measures (but not all) was poorer in the presence of the phone distraction task. However, no discernable learning effects were obtained on either the driving task measures, the phone task measures, or their combination. We concluded that the reason for the absence of any practice effect was that the driving task was too easy for these participants, and that they reached their asymptotic level already on the first session.

To further examine learning/practice effects, in the present study the driving task difficulty was increased by (1) requiring the drivers to drive at higher speeds than before, and (2) by testing two more groups of drivers: novice drivers with minimal driving experience and older drivers who were expected to have more difficulty in time-sharing the driving and phone tasks (Hancock et al, 2003; McKnight and McKnight, 1993; Strayer and Johnston, 2001). Thus, the purpose of the study was to see if, when the driving task is sufficiently difficult or the driver is less capable, there is a learning effect whereby drivers learn to combine the driving task with the phone task. With respect to the distraction, we used two types of tasks: a math operations task (as in the previous study), and an emotionally-involving conversation. The math operations task has been 
shown to be sufficiently taxing to interfere with driving performance (McKnight and McKnight, 1993; Shinar, et al., 2002), but its validity as a surrogate for a phone conversation is questionable. The conversation task has the needed ecological validity but suffers from the fact that it is much less structured and - to be emotionally-involving has to be individually-tailored to each participant. 


\section{METHOD}

\section{Participants:}

The participants were 30 drivers who all have their own cell phones and have used the phone while driving. The drivers were sampled from three age groups:

- 10 young/novice drivers (6 males, 4 females), all but one 18 years-old (one was 22 years-old), with less than 6 months of driving experience, all reporting "never" or "rarely" using the phone while driving (averaging 45 minutes per week).

- 10 experienced drivers (8 males, 2 females), ages 30 to 33 years-old, with $8-15$ years of driving experience (average $=12$ years), with 8 reporting "occasional" or "frequent" phone use while driving and 2 reporting "rare" phone use while driving (averaging 1.2 hours per week).

- 10 older drivers ( 7 males, 3 females), 60 to 71 years-old, with an average of 35 years of driving experience, all reported using the phone while driving - from "rarely" to "frequently" (averaging 45 minutes per week).

The rationale for selecting these particular age groups is that the novice drivers are very experienced in using the phone but not in driving, and their psychomotor abilities to integrate dual tasks is the greatest. The experienced drivers are experienced in both tasks and in combining them as well. The older drivers typically do not time-share phone conversation with driving, and are the least capable of learning to combine these tasks.

\section{Equipment and Measurement Devices:}

The participants drove a STISIM PC-computer-based simulator, installed in a cab of a passenger car. The driver's field of view was projected on an 8x6-foot screen located in front of the car, subtending a 40-degree horizontal visual field with a 1:1 magnification ratio. The STISIM is a fixed-base simulator with interactive steering wheel, brake pedal, and accelerator. The simulator has a scene definition language that allows flexibility in the design of the route and traffic. For this study, the roadway consisted of a relatively straight two-lane highway with few turns and little traffic. There were cars that occasionally came towards the participants' vehicles in the opposite lanes, and other cars that passed them. However, except in the car-following task, on no occasion did the driver come up to a car proceeding at a slower speed.

Built in with the driving task was an "off-road" secondary target detection task. Its purpose was to add to the driver's information processing load in an otherwise easy drive. It consisted of two diamond shapes positioned on the right-top and left-top corners of the screen. In a random manner, one of them would change shape from a diamond to a triangle, and would remain in that shape for 5 seconds. The participant's task was to move the signal handle in the direction of the diamond that changed shape. A total of 12 signals were given on each session, with 0-3 signals on each of nine 3-minute segments. Because in some conditions no signal appeared at all, performance data on this task were not analyzed as a function of the distractions. 
To simulate the cellular phone demands, two hands-free dual tasks consisting of listening and responding to verbal questions were used. All of the information was given through a dedicated speaker installed on the dashboard to the left of the steering wheel. Two different kinds of distracting "phone tasks" were given:

1. Math operations task - the drivers were presented with a sequence of numbers and operations and asked to provide the final answer. For example: [ $3+6+9-2$ +4) $\mathrm{X} 2+6] / 2=$ ? Answer: 23. This task was identical to the one used by McKnight and McKnight (1993). The numbers were presented at the rate of 1 per 2 seconds, and the participants were allowed five seconds for their final response.

2. Emotionally-involving conversation - Prior to the driving, as part of the background interview, the participant was asked about his/her school, work, social habits, hobbies and interests. Based on these, a series of questions were developed to generate conversations that would be emotionally challenging. The topics differed for the different age groups and different participants within each age group. For example, if the driver was an avid sports fan of a specific team then one conversation topic would be about how that team is doing, challenging the participant that his/her team has not been doing that great lately. As in a real phone conversation, the experimenter could not see the driver or the driving scene during the conversation, and thus its pace (as far as the experimenter was concerned) was uninfluenced by the driving task.

\section{Procedure:}

Each participant participated in 5 sessions, extending over 14 days with no less than one day between sessions and no more than 4 days between sessions. The first session lasted close to an hour and the rest of the sessions lasted slightly over 30 minutes.

In session 1 the participant was given a brief questionnaire, interviewed about his/her hobbies and interests, and then asked to drive the simulator without any distracting tasks for a 4-minute practice session. Next the participant received three minutes of practice in each of the two distracting "phone" tasks. The length of this practice session was based on previous research experience with this simulator. The practice period was followed by a short break after which the experimental session began.

Each experimental session consisted of three 9-minute blocks of driving - each divided further into three 3-minute segments. The three segments consisted of a random order of the three levels of the distracting phone tasks: no distraction, math computations, and an emotionally-involving conversation. There were no breaks between the segments within each 9-minute driving block, but there was a one-minute break between driving blocks. The three blocks consisted of three "speed conditions": driving while attempting to maintain a constant speed of $50 \mathrm{mph}$, driving while attempting to maintain a constant speed of $65 \mathrm{mph}$, and driving while following a car whose speed varied between 50 and $65 \mathrm{mph}$. The order of the phone conditions (within the blocks) and the order of the speed conditions (between the blocks) were counterbalanced within and between subjects. 
All drivers were asked to drive as close as possible to the center of the lane. In the constant-speed conditions, whenever the driver's speed deviated from the required speed by $10 \mathrm{mph}$ the driver was reminded of the required speed and asked to resume it. This actually happened very rarely, and only on the first session.

At the end of each session the participants were asked to fill out a questionnaire relating to their perceptions of their task that day. There were seven questions, and for each question the participants had to rate their feelings on a scale of 1 to 9 , with 1 indicating "very little" and 9 indicating "very much." The questions were:

- How mentally difficult was today's task (from very little to very much)?

- How physically difficult was today's task (from very little to very much)?

- What was the pace of work required today (from very slow to very fast)?

- How successful were you in driving the task today (from not at all to very successful)?

- How hard did you have to work (from not hard at all to very hard)?

- How tense or stressed were you when performing the task (from not at all to very much)?

- In general, how loaded did you feel performing the task (from not at all to very much)?

\section{Design:}

The study design was a within subject repeated measures paradigm. Performance was evaluated on the basis of driving-related measures and phone-related measures.

The independent variables whose effects on driving-related measures were evaluated included:

- Driving condition/speed: $50 \mathrm{mph}$ (slow speed), $65 \mathrm{mph}$ (fast speed), and car following (with lead vehicle speed varying between $50 \mathrm{mph}$ and $65 \mathrm{mph}$ )

- Distracting phone condition: no phone task, arithmetic calculations, and emotionally-involving conversation.

- Practice: Sessions 1 through 5.

- Driver age/experience: young, intermediate, and old

The driving-related dependent measures included the following:

- Average speed

- Speed variance

- Average lane position

- Lane position variance

- Steering variability

- Accidents/crashes (including going off the road)

- Reaction time to distracting peripheral signals (analyzed to a limited extent because the signal did not appear on all conditions for all participants). 
The distraction-related dependent measure was the number of correct responses in the math operations task. It was evaluated relative to the three independent measures (driving condition/speed, practice, and driver age/experience).

The subjective evaluation scores - provided at the end of each session - could only be evaluated relative to the practice effect. 


\section{RESULTS}

In general it was assumed that the effects of the five days of driving and listening to the phone would generate a gradual improvement in both the driving tasks and the phone listening tasks. The critical issue is whether there is a statistical interaction between the learning effects and the phone conditions, and whether that interaction differs for the three different age groups. Such an interaction would be manifested in a diminishing difference in the driving performance as a function of the distracting phone condition from Day 1 (with driving performance being significantly poorer with the distraction than without it) to Day 5.

This general hypothesis - that the interference from the distracting task diminishes over time -- is tested below on each of the driving measures: average speed, root-mean-square (RMS) of speed, average lane position, lane position RMS, average extent of the steering wheel turns, and the subjective workload experienced by the drivers. To test these effects a four-way partially repeated measures analysis of variance (ANOVA) with Age (between subjects), Speed, Distraction, and Day (within subjects) was performed on each of the dependent measures. The general model used for all the analyses was StatSoft's (2001) General Linear Model, Repeated Measures ANOVA.

\section{Effects of Distraction on Average Speed}

A distracting task should make it more difficult for the drivers to maintain the desired speed, so that the requirement to perform the distracting phone task should cause drivers to lower their driving-related information processing and drive at a lower speed than required.

The results of the four-way ANOVA on the average speed are reproduced in table 1 . As can be seen from this table, all of the main effects and most of the interactions are statistically significant. An examination of the mean speed levels indicated that actual average speed was - as expected - highest for the $65 \mathrm{mph}$ condition and lowest for the 50 mph condition. The interaction between Speed and Day is depicted in figure 1, from which it can be seen that the average speed was fairly constant - and essentially as desired - for the $50 \mathrm{mph}$ and the car-following condition. It was higher, and increased over the five days for the $65 \mathrm{mph}$ condition, never quite reaching the required $65 \mathrm{mph}$. These results indicate that the $65 \mathrm{mph}$ requirement was in fact much more demanding than the other two lower speeds, but that over time drivers managed to approach the desired level.

The differential effects of age on speed are displayed in figure 2, where it can be seen that the effects of age are restricted to the high-speed condition only. At all required speeds, there are essentially no differences between the two younger groups. However the older drivers' ability to keep the required speed diminishes as the required speed goes up, so that for the $65 \mathrm{mph}$ requirement, their average speed is approximately $4 \mathrm{mph}$ less than that of the younger drivers. Also apparent from this figure is the fact that even for the younger participants, driving at $65 \mathrm{mph}$ was sufficiently challenging that they could not 
achieve it immediately, and in fact, there is a very noticeable learning curve even for them.

The effects of the distraction task on the driving of the three age groups are presented in figure 3. It is apparent that the distraction had an impact on speed, but the direction of the effect was unexpected, with speed being the lowest with no distraction, and the highest with the distracting conversation. Of the two distracting tasks, the math operations caused the drivers to drive at lower speeds than when the distracting task was a conversation. Although the interaction indicates that the relative effect of distraction is greater on the younger than the older drivers (based on the formers' higher speeds) this effect is not a strong one, and the effects of age and distraction do seem almost additive.

Table 1: Analysis of Variance on the Effects of Age, Day, Speed Condition, and Distraction on Average Speed.

\begin{tabular}{|c|c|c|c|c|c|}
\hline \multirow[b]{2}{*}{ Effect } & \multicolumn{5}{|c|}{$\begin{array}{l}\text { Repeated Measures Analysis of Variance (avgspee } \\
\text { Sigma-restricted parameterization } \\
\text { Effective hypothesis decomposition }\end{array}$} \\
\hline & \begin{tabular}{|l|} 
SS \\
\end{tabular} & \begin{tabular}{c|} 
Degr. of \\
Freedom \\
\end{tabular} & MS & $\mathrm{F}$ & $p$ \\
\hline Intercept & 4216515 & 1 & 4216515 & 70733.49 & 0.000000 \\
\hline age & 1066 & 2 & 533 & 8.94 & 0.001047 \\
\hline Error & 1610 & 27 & 60 & & \\
\hline DAY & 376 & 4 & 94 & 11.14 & 0.000000 \\
\hline DAY*age & 102 & 8 & 13 & 1.51 & 0.162737 \\
\hline Error & 910 & 108 & 8 & & \\
\hline SPEED & 28093 & 2 & 14046 & 1430.48 & 0.000000 \\
\hline SPEED*age & 504 & 4 & 126 & 12.82 & 0.000000 \\
\hline Error & 530 & 54 & 10 & & \\
\hline DISTRACT & 318 & 2 & 159 & 91.20 & 0.000000 \\
\hline DISTRACT*age & 25 & 4 & 6 & 3.52 & 0.012627 \\
\hline Error & 94 & 54 & 2 & & \\
\hline DAY*SPEED & 653 & 8 & 82 & 11.68 & 0.000000 \\
\hline DAY*SPEED*age & 192 & 16 & 12 & 1.72 & 0.045173 \\
\hline Error & 1511 & 216 & 7 & & \\
\hline DAY*DISTRACT & 567 & 8 & 71 & 20.31 & 0.000000 \\
\hline $\mathrm{DAY}^{*}{ }^{\mathrm{DISTRACT}}{ }^{*}$ age & 179 & 16 & 11 & 3.21 & 0.000056 \\
\hline Error & 754 & 216 & 3 & & \\
\hline SPEED*DISTRACT & 11110 & 4 & 278 & 85.69 & 0.000000 \\
\hline SPEED*DISTRACT*age & 30 & 8 & 4 & 1.16 & 0.328326 \\
\hline Error & 350 & 108 & 3 & & \\
\hline DAY*SPEED*DISTRACT & 862 & 16 & 54 & 16.28 & 0.000000 \\
\hline $\mathrm{DAY}^{*}$ SPEED*DISTRACT*age & 253 & 32 & 8 & 2.39 & 0.000052 \\
\hline Error & 1429 & 432 & 3 & & \\
\hline
\end{tabular}


Figure 1. The Effects of Day and Required Speed on the Drivers' Average Speed.

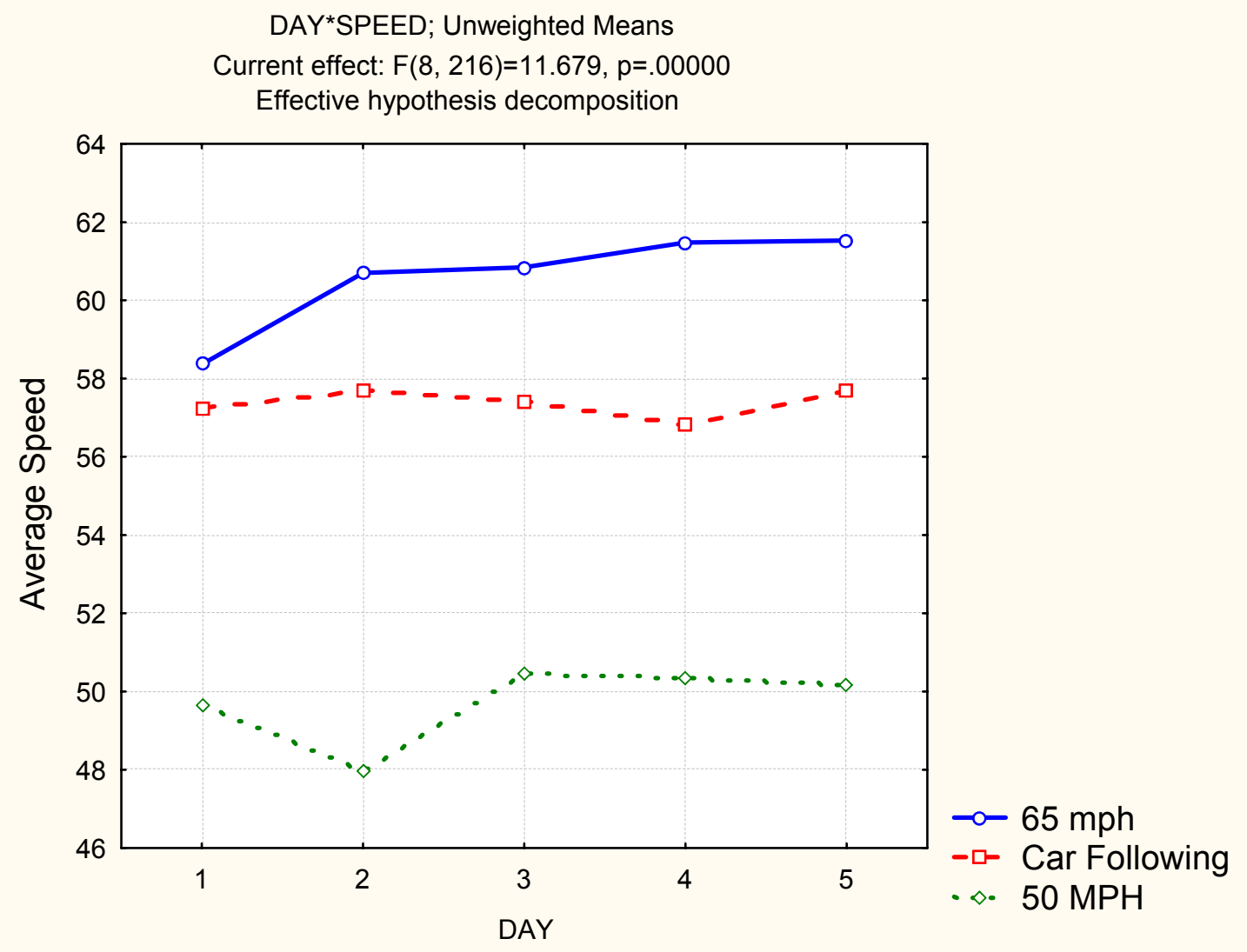


Figure 2. The Effects of Day, Required Speed, and Age on the Drivers' Average Speed.

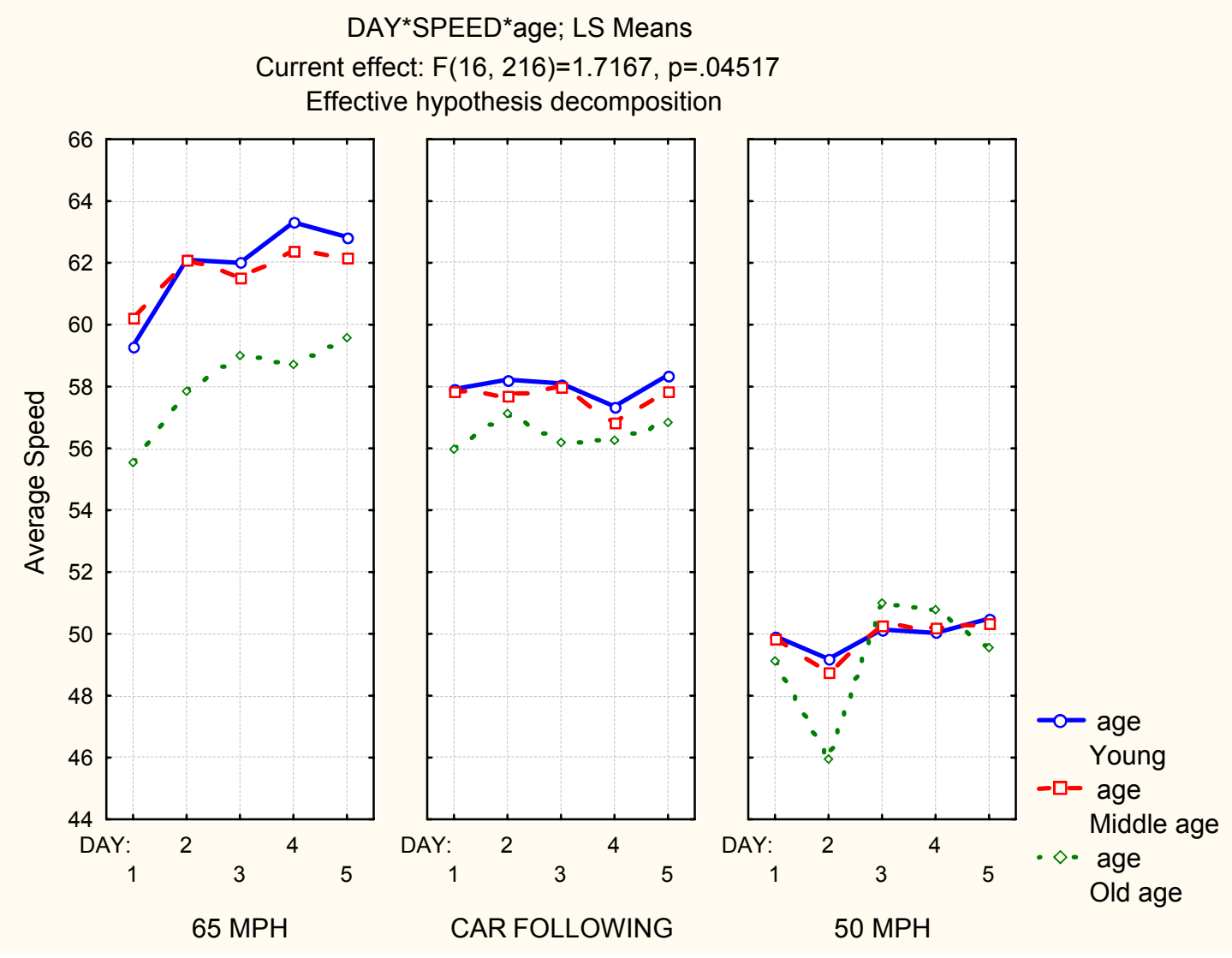


Figure 3. The Effects of Distraction and Age on the Drivers' Average Speed.

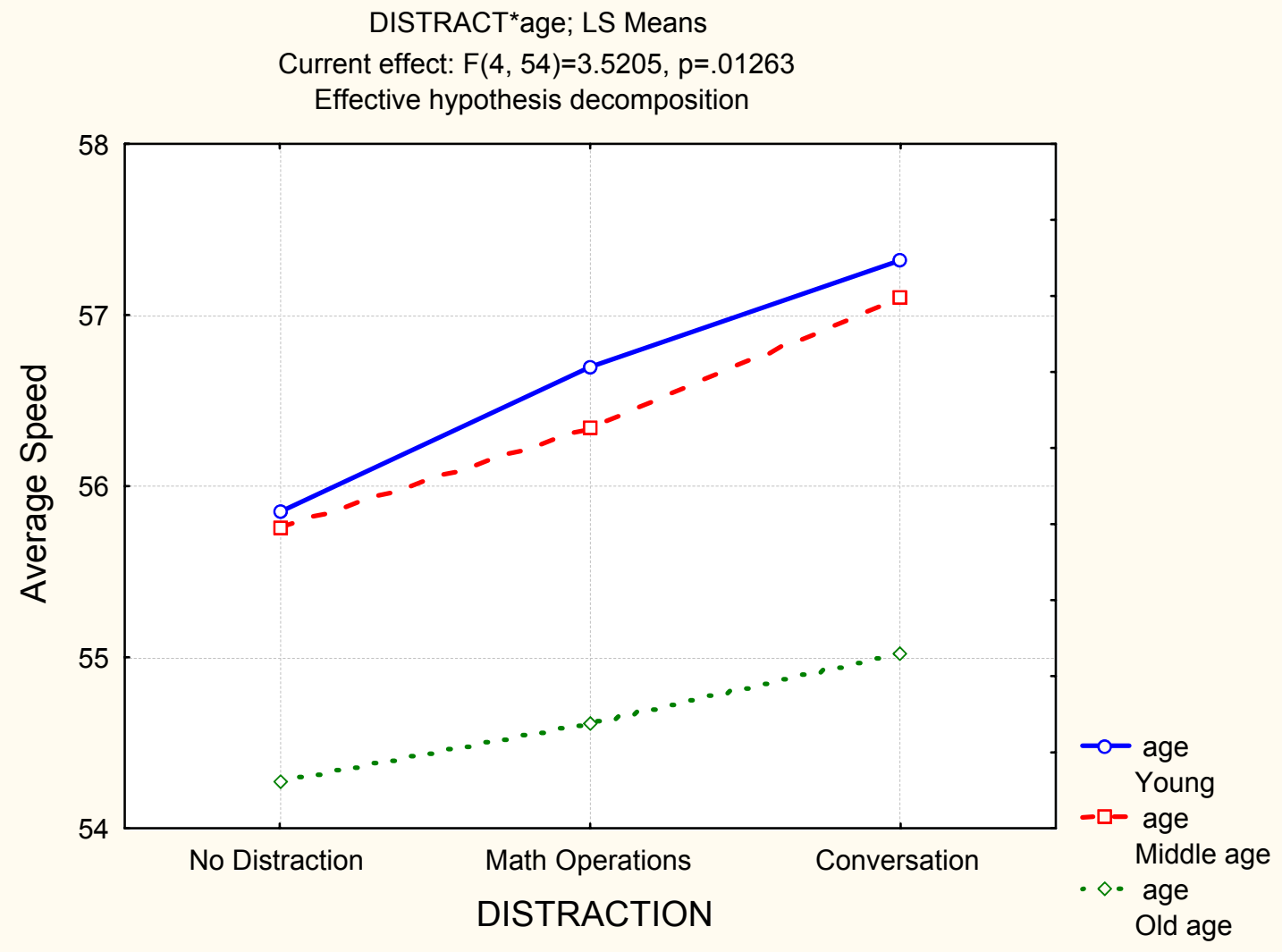

The effects of practice in diminishing the distraction effects of the phone task are shown in figure 4, which shows the interaction of Day, Speed, and Distraction on the average speed. The interaction indicates that with the two lower speeds (50 mph and carfollowing) there is no apparent learning in the sense that the speed does not change over time. In these two conditions there is a ceiling effect showing that already on Day 1 all groups of drivers are able to maintain the required speed. In contrast, with the required high speed of $65 \mathrm{mph}$, there is a learning effect - reflected in an increase in speed over the 5 days, and a diminishing effect of the distraction on the speed: initially the math operations cause a significant reduction in speed relative to the no-distraction and the conversation (which do not differ from each other), but by the end of the $5^{\text {th }}$ day they have no impact on the average speed. This is also indicated by the significant four-way interaction. This interaction showed that in the $50 \mathrm{mph}$ speed condition there were essentially no effects of practice, age or distraction. In the car-following mode there were also no effects of practice or age, but the average speed with no distraction was very stable at approximately $55 \mathrm{mph}$, while with the distracting task it was more variable and significantly higher. Only at the most demanding speed of $65 \mathrm{mph}$, do we see the effects of learning, distraction, and age. All groups show a learning effect, but the relationship between the learning and the distraction is different for the different age groups, as can be seen in figure 5. The youngest drivers do not show any deleterious effects of the distracting task. The middle-aged group initially performs better with no-distraction and 
conversation than with the distracting math task, but by the fifth session their performance is the same regardless of the presence or absence of distraction. The older drivers show the greatest effect of the distraction initially, but they too are able to combine the two tasks by the fifth session, though their progress is much more variable.

Figure 4. The Effects of Distraction, Practice and Required Speed on the Drivers' Average Speed.

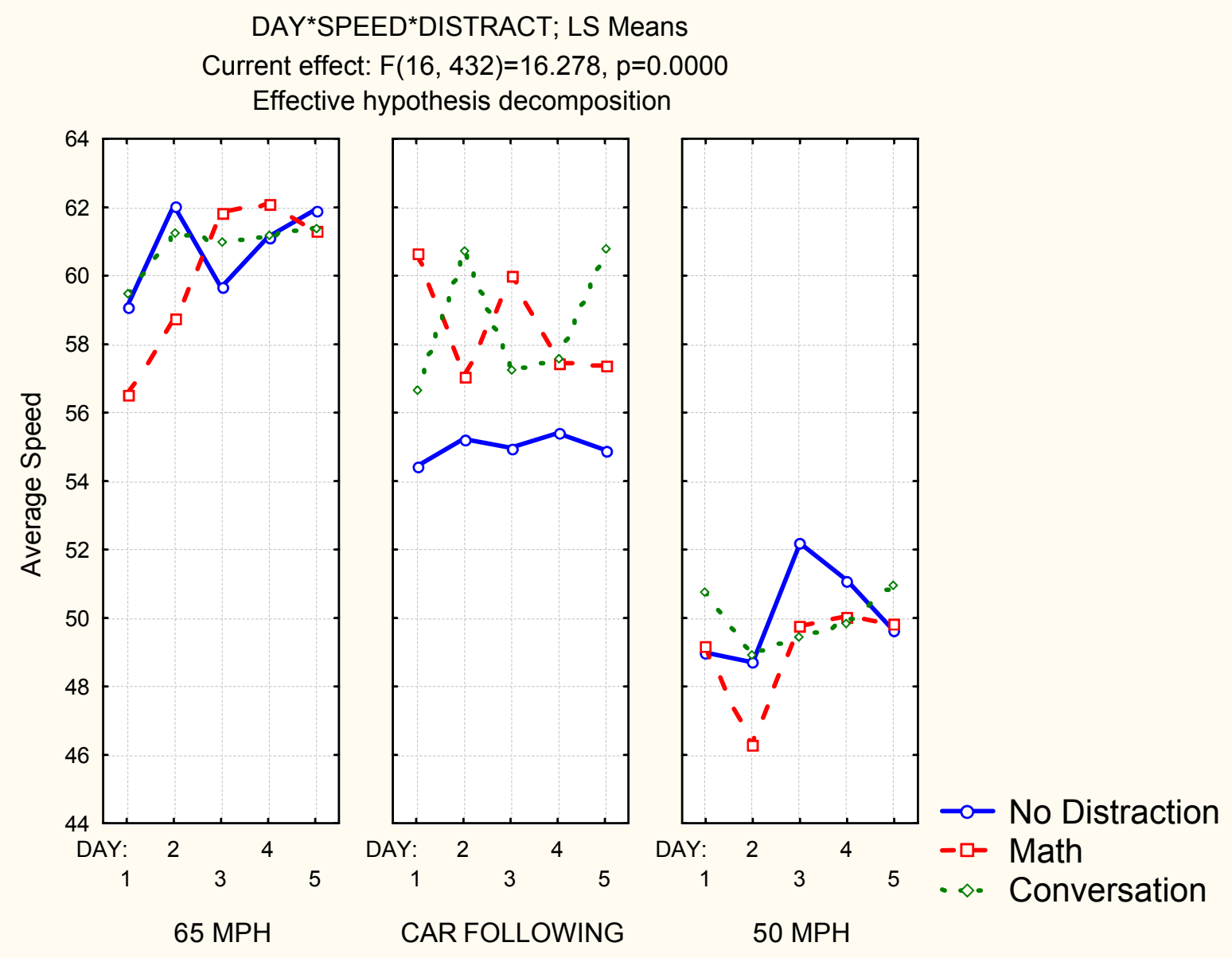


Fig. 5. The Effects of Distraction, Practice and Age on the Drivers' Average Speed when required to maintain a speed of $65 \mathrm{mph}$.

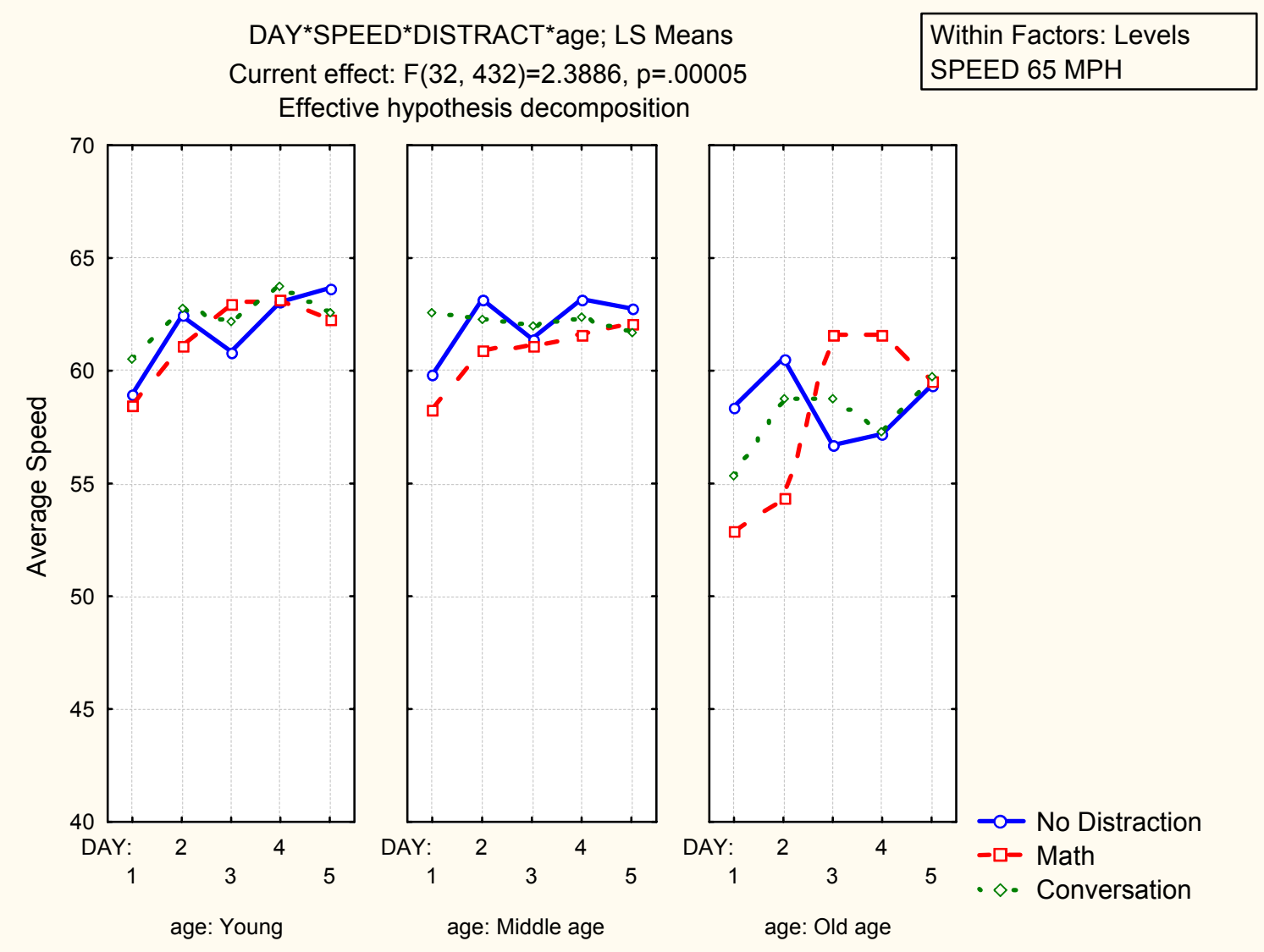

\section{Effects of Distraction on Speed Variance}

A distracting task should make it more difficult for the drivers to maintain the desired speed, and consequently their variance around their mean speed should increase with increasing distraction.

The results of the four-way ANOVA on the speed variance are reproduced in table 2. As can be seen from the table, all but one of the effects and interactions were statistically significant. 
Table 2. Analysis of Variance on the Effects of Age, Day, Speed Condition, and Distraction on Speed Variance.

\begin{tabular}{|c|c|c|c|c|c|}
\hline \multirow[b]{2}{*}{ Effect } & \multicolumn{5}{|c|}{$\begin{array}{l}\text { Repeated Measures Analysis of Variance (varspeed } \\
\text { Sigma-restricted parameterization } \\
\text { Effective hypothesis decomposition }\end{array}$} \\
\hline & SS & $\begin{array}{l}\text { Degr. of } \\
\text { Freedom }\end{array}$ & MS & $\mathrm{F}$ & $p$ \\
\hline Intercept & 35930.48 & 1 & 35930.48 & 744.9535 & 0.000000 \\
\hline Age & 1422.92 & 2 & 711.46 & 14.7509 & 0.000047 \\
\hline Error & 1302.26 & 27 & 48.23 & & \\
\hline DAY & 1011.18 & 4 & 252.79 & 26.9747 & 0.000000 \\
\hline DAY*Age & 222.07 & 8 & 27.76 & 2.9620 & 0.004908 \\
\hline Error & 1012.12 & 108 & 9.37 & & \\
\hline SPEED & 2331.43 & 2 & 1165.71 & 187.5237 & 0.000000 \\
\hline SPEED*Age & 149.86 & 4 & 37.46 & 6.0267 & 0.000439 \\
\hline Error & 335.68 & 54 & 6.22 & & \\
\hline DISTRACT & 215.23 & 2 & 107.61 & 44.8838 & 0.000000 \\
\hline DISTRACT*Age & 9.50 & 4 & 2.38 & 0.9910 & 0.420404 \\
\hline Error & 129.47 & 54 & 2.40 & & \\
\hline DAY*SPEED & 1743.01 & 8 & 217.88 & 51.5541 & 0.000000 \\
\hline DAY*SPEED*Age & 223.78 & 16 & 13.99 & 3.3095 & 0.000035 \\
\hline Error & 912.85 & 216 & 4.23 & & \\
\hline DAY*DISTRACT & 1330.85 & 8 & 166.36 & 59.5925 & 0.000000 \\
\hline DAY*DISTRACT*Age & 214.60 & 16 & 13.41 & 4.8048 & 0.000000 \\
\hline Error & 602.98 & 216 & 2.79 & & \\
\hline SPEED*DISTRACT & 611.41 & 4 & 152.85 & 39.3604 & 0.000000 \\
\hline SPEED*DISTRACT*Age & 105.14 & 8 & 13.14 & 3.3841 & 0.001673 \\
\hline Error & 419.41 & 108 & 3.88 & & \\
\hline DAY*SPEED*DISTRACT & 1856.23 & 16 & 116.01 & 45.0814 & 0.000000 \\
\hline DAY*SPEED*DISTRACT*Age & 611.46 & 32 & 19.11 & 7.4251 & 0.000000 \\
\hline Error & 1111.73 & 432 & 2.57 & & \\
\hline
\end{tabular}

Looking first at the effects of age and practice we can see from figure 6 , that older drivers had more difficulty at the task, manifesting much greater variance than the two younger groups, which did not differ from each other. Some learning is apparent for all groups, though the younger two groups' variance nearly levels off after the $2^{\text {nd }}$ day, while the older drivers continue to improve on all days. On their last day all groups perform at the same level, suggesting that additional practice would not have yielded significant further improvements for any of the groups. The main effect of practice, across all conditions and driver groups was almost linear, with the speed variance decreasing from 6.5, to 5.5, to $5.3,4.6$, and to 3.9 , from Day 1 to Day 5, respectively. 
Figure 6. The Effects of Practice and Age on the Drivers' Speed Variance.

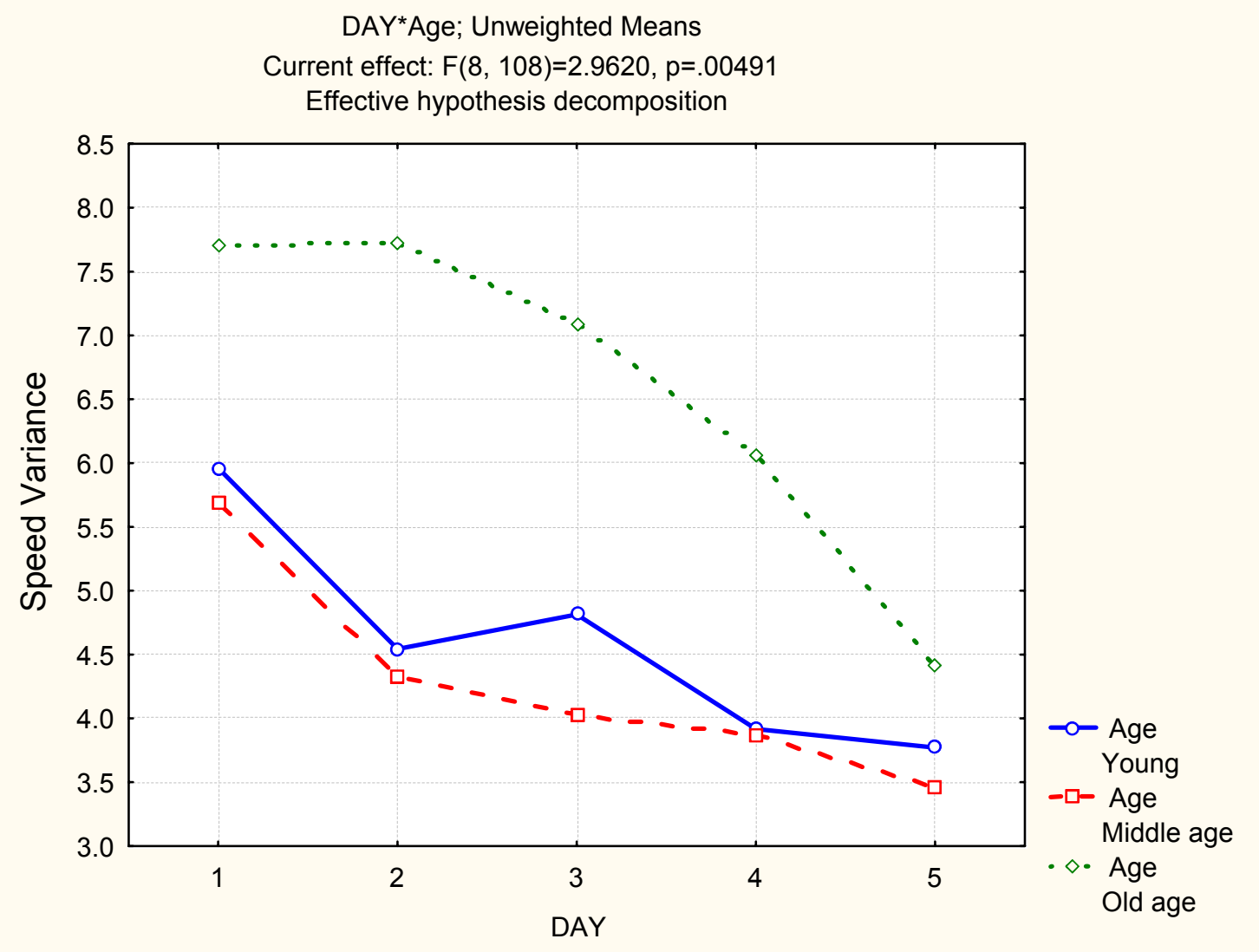

The effects of the required speed and the interactions of speed with age and practice on the speed variance are demonstrated in figure 7 . Whereas the difficulties that older people had in maintaining average speed were mostly in the high $65 \mathrm{mph}$ condition, their inability to drive smoothly at the required speed - with minimal variance around their average speed - was apparent and significant at all three speed conditions. Older drivers had a much greater speed variance than the younger two groups and showed much more of a learning effect than them. For all groups the variance was highest at the most demanding $65 \mathrm{mph}$ condition, and the learning effects were greatest at the most demanding $65 \mathrm{mph}$ condition. Thus, in the easier car-following and lower-speed conditions, all three groups eventually converged on the $5^{\text {th }}$ day, but in the more difficult $65 \mathrm{mph}$ condition, the older drivers retained the higher variance throughout. 


\section{Figure 7. The Effects of Speed, Practice and Age on the Drivers' Speed Variance}

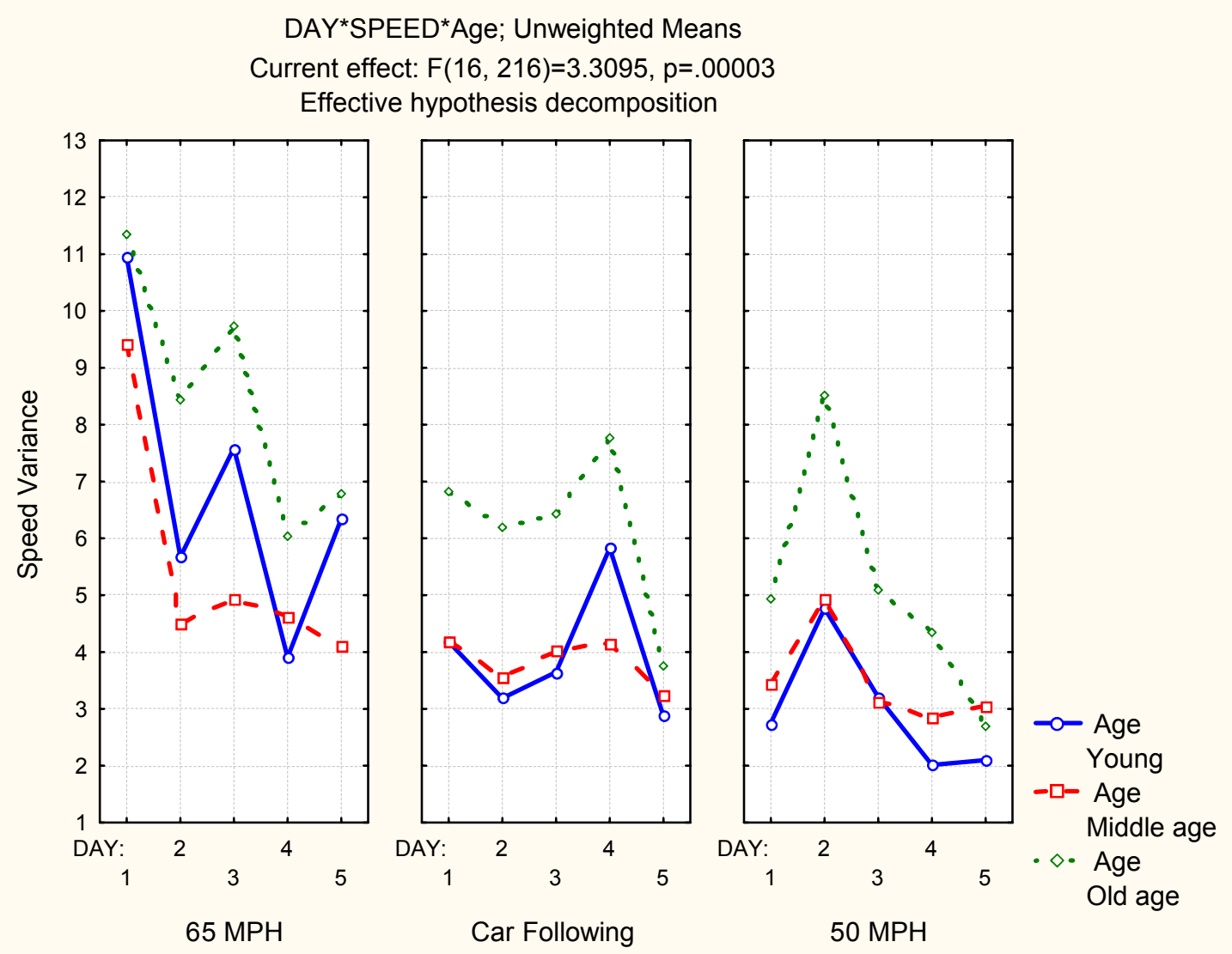

The main effect of distraction on speed variance was significant with an average variance of $5.2 \mathrm{mph}$ for the no-distraction condition, $4.6 \mathrm{mph}$ for the conversation distraction, and $5.6 \mathrm{mph}$ for the math operations distraction. Thus, the speed variance was significantly higher with distraction than in the control condition only when the phone task required math operations. The requirement to converse, inexplicably, actually lowered the variance relative to the control condition. The absence of a significant interaction with age indicated that this pattern was identical for all age groups. The significant interaction of Distraction and Day is displayed in figure 8. While the distraction clearly shows the learning effect, the effects of the distraction and its interaction with learning are not very consistent. Nonetheless, the figure does reflect the fact that speed variance disparities between the no-distraction and the math distraction conditions are much larger on Day 2 than they are on Days 3 and 4. However, on Day 1, the variance is actually smaller with the distracting conversation (but not with the math operations) than without it. 


\section{Figure 8. The Effects of Distraction and Practice on the Drivers' Speed Variance}

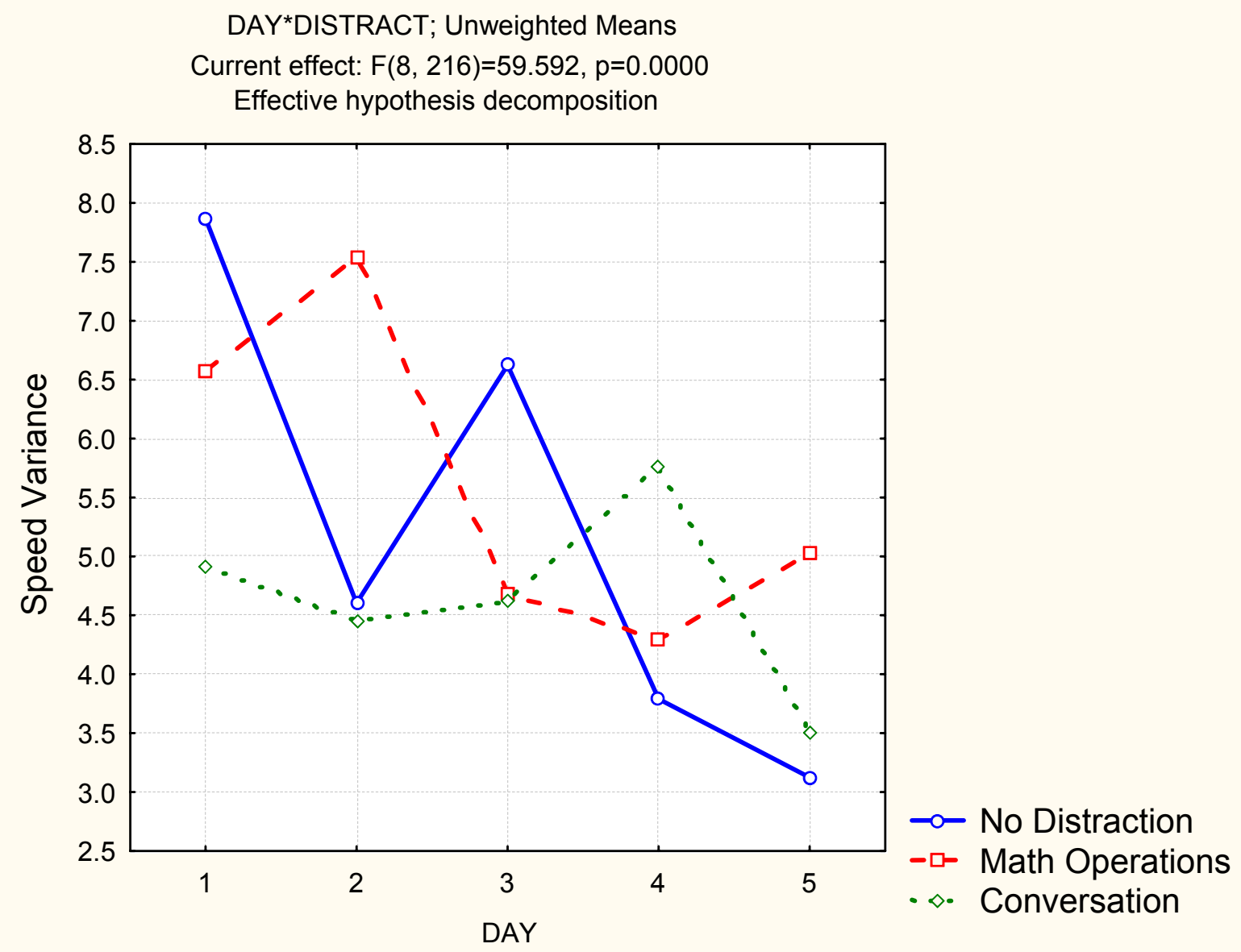

Further examination of the four-way interaction between the variables, revealed that in the car following and $50 \mathrm{mph}$ condition, the older drivers showed a learning effect while the younger drivers had essentially the same variance on all days - the level equivalent to the one eventually reached by the older drivers on Day 5 . However, in the most demanding $65 \mathrm{mph}$ condition, displayed in figure 9 , the effects of practice - though not very consistent - were significant for the younger and older drivers, and less so for the middle-aged drivers. For all drivers, speed variance in the presence of the demanding math operations decreased over the first four days, but then (inexplicably) increased on Day 5 for the younger and older drivers. 
Figure 9. The Effects of Distraction, Practice and Age on the Drivers' Speed Variance when Required to Maintain a Speed of $65 \mathrm{mph}$.

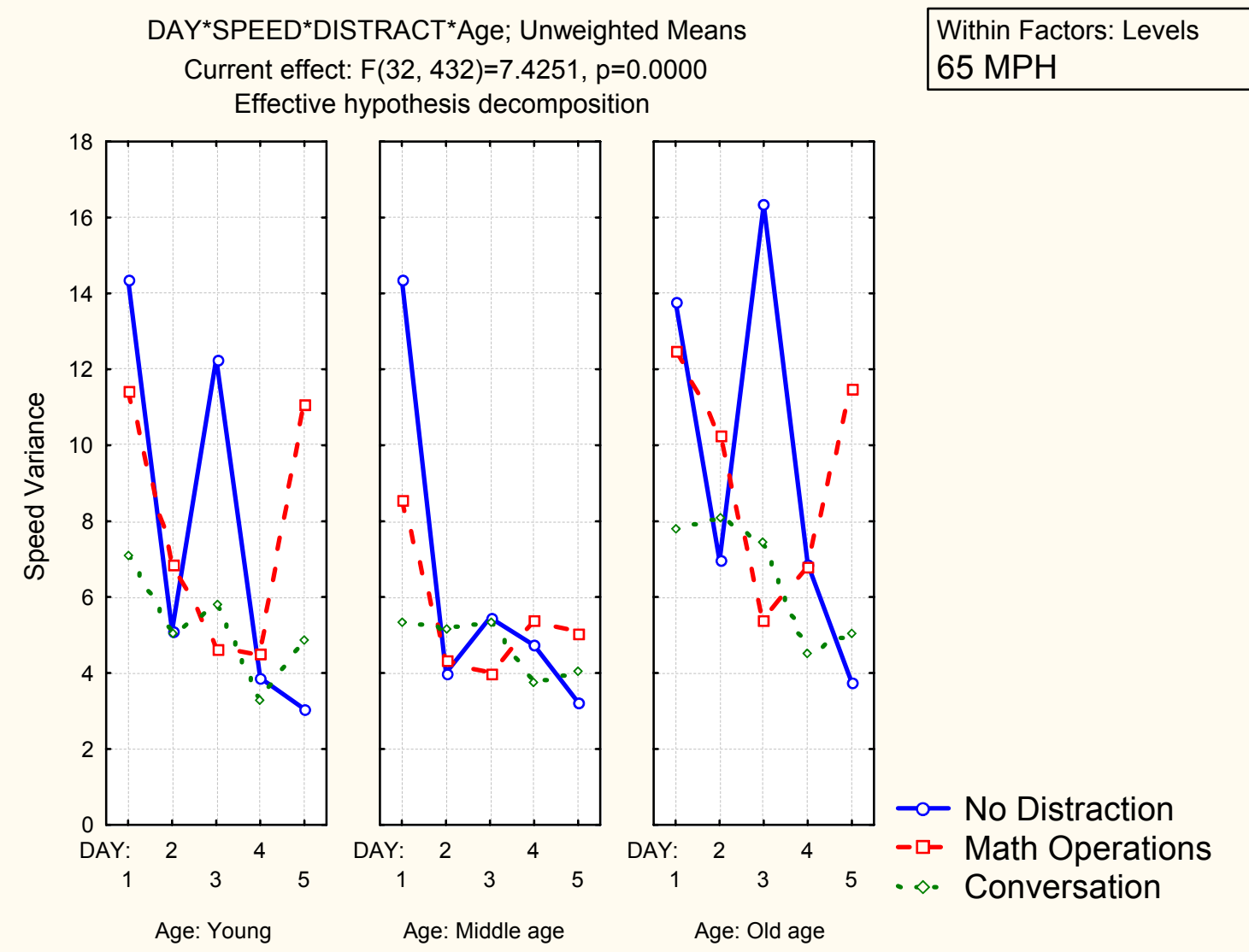

\section{Effects of Distraction on the Average Lane Position}

In the driving simulator, lane position is measured relative to the center of the road. Since the lane width was 8.33 feet, a driver who perfectly centers his/her car in the middle of the lane would have an average lane position of 4.16 feet. Drivers who keep their car closer to the shoulder than to the median would have an average lane position greater than $4.16 \mathrm{ft}$, and those who keep it closer to the median than to the shoulder would have an average lane position less than $4.16 \mathrm{ft}$. A summary of the results of the analysis of variance on the average lane position is presented in table 3 . 
Table 3. Analysis of Variance on the Effects of Age, Day, Speed Condition, and Distraction on Average Lane Position.

\begin{tabular}{|c|c|c|c|c|c|}
\hline \multirow[t]{2}{*}{ Effect } & \multicolumn{5}{|c|}{$\begin{array}{l}\text { Repeated Measures Analysis of Variance (avglanepo } \\
\text { Sigma-restricted parameterization } \\
\text { Effective hypothesis decomposition }\end{array}$} \\
\hline & SS & \begin{tabular}{|c|} 
Degr. of \\
Freedom \\
\end{tabular} & MS & $\mathrm{F}$ & $p$ \\
\hline Intercept & 31185.91 & 1 & 31185.91 & 3640.894 & 0.000000 \\
\hline Age & 126.28 & 2 & 63.14 & 7.371 & 0.002790 \\
\hline Error & 231.27 & 27 & 8.57 & & \\
\hline DAY & 4.65 & 4 & 1.16 & 1.328 & 0.264114 \\
\hline DAY*Age & 5.51 & 8 & 0.69 & 0.787 & 0.614875 \\
\hline Error & 94.57 & 108 & 0.88 & & \\
\hline SPEED & 1.08 & 2 & 0.54 & 1.422 & 0.250210 \\
\hline SPEED*Age & 1.70 & 4 & 0.43 & 1.115 & 0.359220 \\
\hline Error & 20.60 & 54 & 0.38 & & \\
\hline DISTRACT & 1.01 & 2 & 0.51 & 2.417 & 0.098782 \\
\hline DISTRACT*Age & 0.65 & 4 & 0.16 & 0.772 & 0.548522 \\
\hline Error & 11.34 & 54 & 0.21 & & \\
\hline DAY*SPEED & 21.57 & 8 & 2.70 & 8.868 & 0.000000 \\
\hline DAY*SPEED*Age & 9.51 & 16 & 0.59 & 1.955 & 0.017288 \\
\hline Error & 65.68 & 216 & 0.30 & & \\
\hline DAY*DISTRACT & 13.87 & 8 & 1.73 & 8.901 & 0.000000 \\
\hline DAY*DISTRACT ${ }^{*}$ Age & 3.36 & 16 & 0.21 & 1.079 & 0.376151 \\
\hline Error & 42.07 & 216 & 0.19 & & \\
\hline SPEED*DISTRACT & 8.93 & 4 & 2.23 & 12.437 & 0.000000 \\
\hline SPEED*DISTRACT*Age & 2.89 & 8 & 0.36 & 2.010 & 0.051798 \\
\hline Error & 19.39 & 108 & 0.18 & & \\
\hline DAY*SPEED*DISTRACT & 28.15 & 16 & 1.76 & 10.960 & 0.000000 \\
\hline $\mathrm{DAY}^{*}$ SPEED*DISTRACT*Age & 6.13 & 32 & 0.19 & 1.193 & 0.220459 \\
\hline Error & 69.36 & 432 & 0.16 & & \\
\hline
\end{tabular}

There was a significant main effect of age on lane position, with the oldest drivers being closest to the center of the lane, at an average position of $4.5 \mathrm{ft}$, the middle age drivers maintaining a position farther to the shoulder at $4.7 \mathrm{ft}$, and the youngest staying the farthest to the right at an average of $5.2 \mathrm{ft}$. There was no significant main effect of practice on the average lane position, though there was an interaction between day and speed, and between day, speed, and age. The last three-way interaction is depicted in figure 10. It is difficult to discern a consistent pattern in the two-way interaction (not shown), and it appears that the interaction was due mostly to the difference in the lane position between the $50 \mathrm{mph}$ speed condition and the other two conditions on Day 2, and the absence of such a difference (or any significant differences) on the other days. The three-way interaction demonstrates that the youngest drivers were clearly different from the other two groups: at all speeds they drove the farthest away from the centerline, and showed essentially no change over the five days of practice at the task. The two older 
driver groups were similar to each other in their distance away from the center of the lane when driving in the car following mode, but differed from each other in the fixed speed mode, with the older drivers driving closest to the center of the road. Furthermore, there was a slight - but albeit noisy - practice effect with the two older groups: getting farther away from the centerline with practice in the $65 \mathrm{mph}$ and car-following conditions.

\section{Figure 10. The Effects of Practice Speed and Age on the Drivers' Average Lane Position}

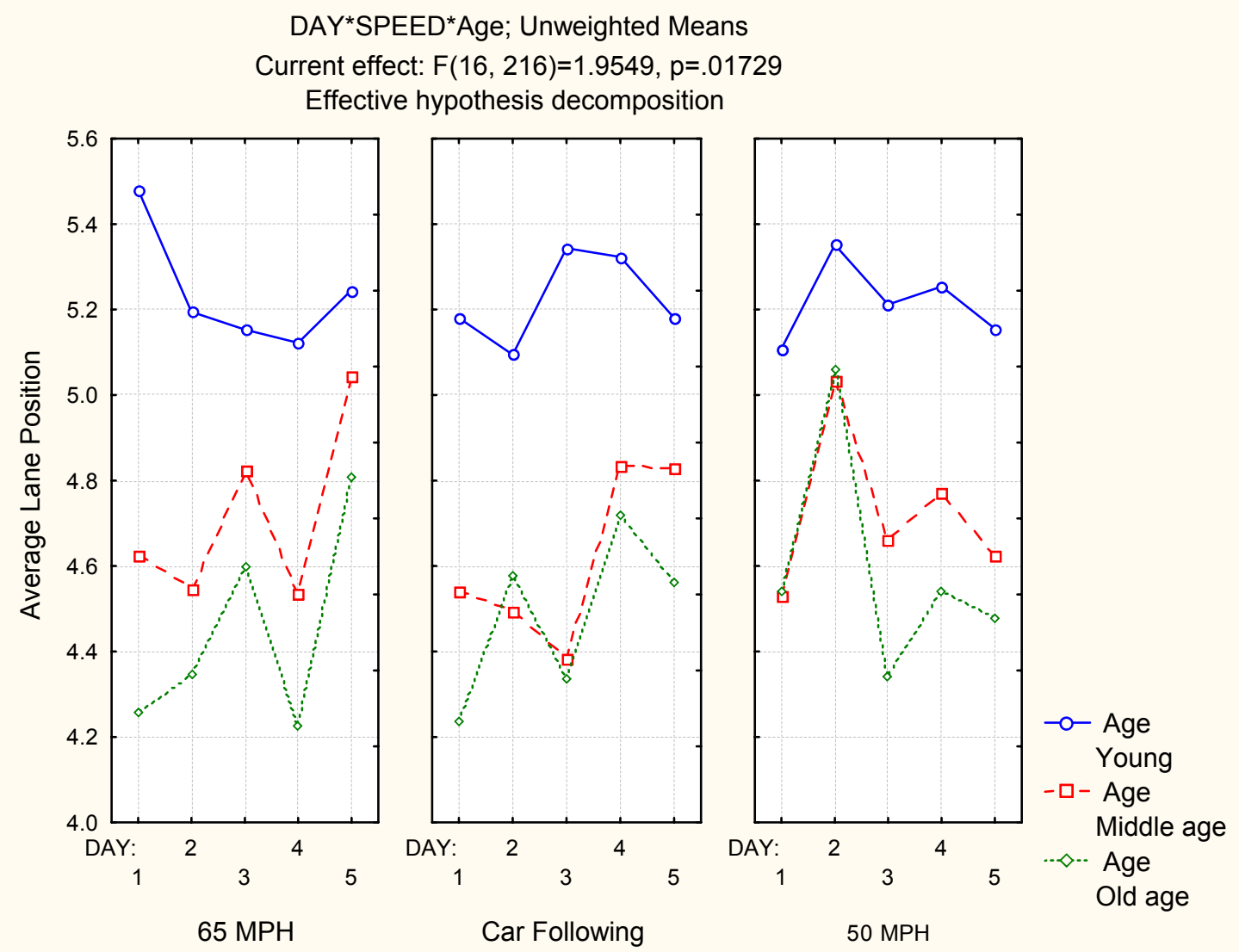

The effect of distraction was only marginally significant, but its interaction with practice was highly significant, as was its interaction with speed. The three-way interaction of day, speed and distraction is depicted in figure 11. The practice-related pattern is quite noisy, but in general there is a practice effect in the $65 \mathrm{mph}$ and car-following condition but not in the easier $50 \mathrm{mph}$ condition. 
Figure 11. The Effects of Distraction, Practice, and Speed on the Drivers' Average Lane Position



There was also a marginally significant interaction between the driver age, required speed and distraction, which is depicted in figure 12. The consistent effects of age are very large, but no consistent patterns appear with respect to the effects of speed or distraction. Furthermore, at the most demanding speed of $65 \mathrm{mph}$, there are no statistically significant differences between the no-distraction and the most difficult distraction of math operations, for any of the age groups. 
Figure 12. The Effects of Distraction, Age, and Speed on the Drivers' Average Lane Position

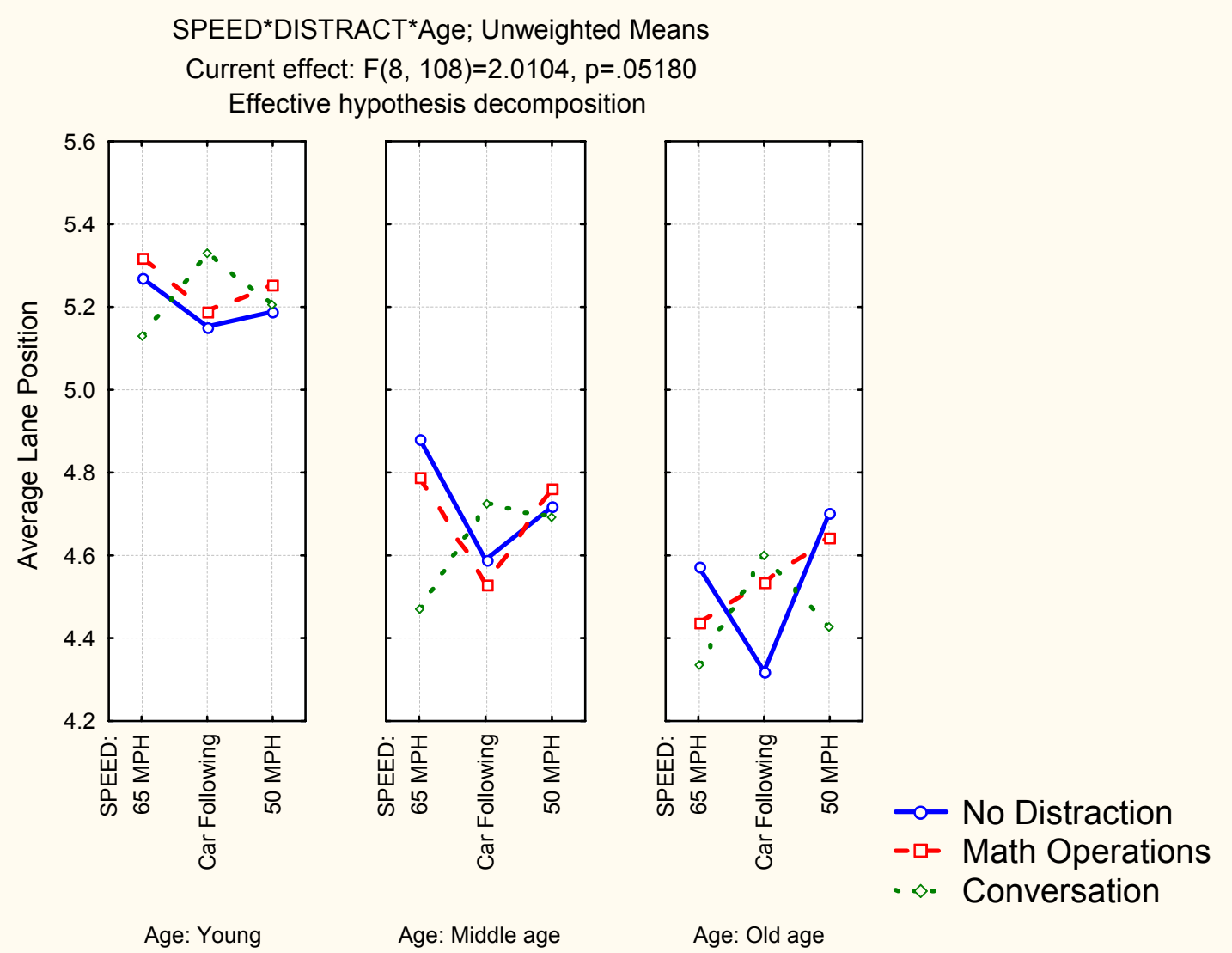

\section{Effects of Distraction on the Variance of Lane Position}

The variance in lane position is an indicator of the driver's stability in maintaining the car within the lane - independently of its average location within the lane. Thus, it was expected that in the presence of a demanding distracting task, the variance would increase relative to the driving without distractions, and that with practice the variance would decrease.

The results of the analysis of variance on the variance in the lane position are presented in table 4 . The only significant main effect was that of age, with the younger drivers being much more stable than the older ones: the youngest drivers had a lane position variance of $0.9 \mathrm{ft}$, the middle age drivers had $1.4 \mathrm{ft}$, and the older drivers had $1.6 \mathrm{ft}$. All the twoway interactions between day, speed, and distraction were also significant, as was the three-way interaction between them. This last interaction is plotted in figure 13. 
Table 4. Analysis of Variance on the Effects of Age, Day, Speed Condition, and Distraction on Variance in Lane Position.

\begin{tabular}{|l|r|r|r|r|r|}
\hline & \multicolumn{5}{|l|}{$\begin{array}{l}\text { Repeated Measures Analysis of Variance (varlanepo } \\
\text { Sigma-restricted parameterization } \\
\text { Effective hypothesis decomposition }\end{array}$} \\
\cline { 2 - 7 } Effect & SS & $\begin{array}{c}\text { Degr. of } \\
\text { Freedom }\end{array}$ & MS & F & p \\
\hline Intercept & 2226.312 & 1 & 2226.312 & 551.0319 & 0.000000 \\
\hline Age & 103.216 & 2 & 51.608 & 12.7735 & 0.000125 \\
\hline Error & 109.087 & 27 & 4.040 & & \\
\hline DAY & 1.049 & 4 & 0.262 & 0.9401 & 0.443744 \\
\hline DAY*Age & 3.112 & 8 & 0.389 & 1.3941 & 0.207201 \\
\hline Error & 30.139 & 108 & 0.279 & & \\
\hline SPEED & 0.376 & 2 & 0.188 & 0.8787 & 0.421178 \\
\hline SPEED*Age & 0.600 & 4 & 0.150 & 0.7000 & 0.595329 \\
\hline Error & 11.568 & 54 & 0.214 & & \\
\hline DISTRACT & 0.571 & 2 & 0.286 & 2.5686 & 0.085982 \\
\hline DISTRACT*Age & 0.963 & 4 & 0.241 & 2.1649 & 0.085301 \\
\hline Error & 6.007 & 54 & 0.111 & & \\
\hline DAY*SPEED & 17.400 & 8 & 2.175 & 15.8110 & 0.000000 \\
\hline DAY*SPEED*Age & 2.721 & 16 & 0.170 & 1.2365 & 0.241953 \\
\hline Error & 29.714 & 216 & 0.138 & & \\
\hline DAY*DISTRACT & 14.089 & 8 & 1.761 & 16.0833 & 0.000000 \\
\hline DAY*DISTRACT*Age & 2.459 & 16 & 0.154 & 1.4033 & 0.141797 \\
\hline Error & 23.652 & 216 & 0.109 & & \\
\hline SPEED*DISTRACT & 8.729 & 4 & 2.182 & 19.2406 & 0.000000 \\
\hline SPEED*DISTRACT*Age & 0.906 & 8 & 0.113 & 0.9982 & 0.441774 \\
\hline Error & 12.249 & 108 & 0.113 & & \\
\hline DAY*SPEED*DISTRACT & 28.194 & 16 & 1.762 & 16.2543 & 0.000000 \\
\hline DAY*SPEED*DISTRACT*Age & 3.838 & 32 & 0.120 & 1.1064 & 0.319386 \\
\hline Error & 46.832 & 432 & 0.108 & & \\
\hline
\end{tabular}

It is obvious from this figure that, with few exceptions, the variance was relatively stable around $1.3 \mathrm{ft}$ when the drivers were in the $50 \mathrm{mph}$ and car-following conditions.

However, in the most demanding situation of maintaining $65 \mathrm{mph}$, the variance varied greatly from day to day in the absence of distraction. It remained quite high when the drivers maintained a conversation over the phone; and reflected significant learning process in the most demanding math operations dual task. Thus, when both the driving task and the phone task were most demanding, a significant learning process was evident in the decreasing variance in lane position, to the point when - on the fifth day - it was actually as low as for any other specific combination of day, speed and distraction ( 0.7 $\mathrm{ft})$. 
Figure 13. The Effects of Distraction, Age, and Speed on the Drivers' Variance in Lane Position

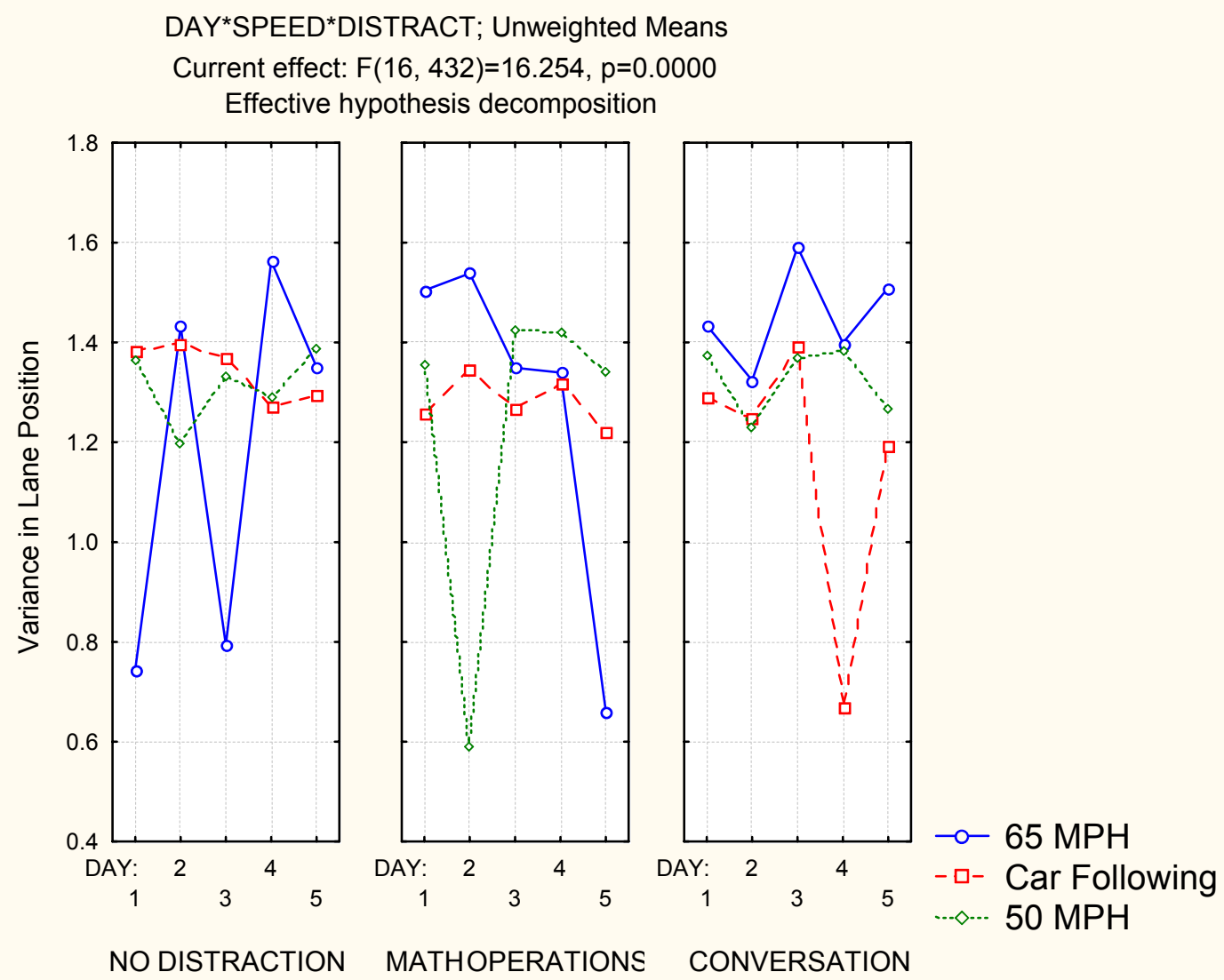

\section{Effects of Distraction on Steering Variability}

Steering variability was measured in terms of the rate and extent of steering wheel corrections. The actual measure was the absolute value of the steering angle deviations in radians/second ( $\mathrm{rads} / \mathrm{s})$. As with lane position variance, the rationale behind the use of this measure is that the greater the load on the driver, the greater the extent and rate of steering corrections that the driver has to make in order to retain the desired lane position.

The results of the four-way analysis of variance on this measure are summarized in table 5. With the exception of one interaction, all main effects and interactions were highly significant, and in the expected direction. Steering variability decreased with practice $(0.67,0.65,0.64,0.60$, and 0.60 on Days 1 through 5 , respectively), with speed $(0.70$ at $65 \mathrm{mph}, 0.66$ in car following, and 0.54 at $50 \mathrm{mph})$, and with age $(0.70$ for the older drivers, 0.57 for the middle age drivers, and 0.63 for the young drivers). The effects of distraction were the only counter-intuitive effects; with steering variability of $0.73 \mathrm{rads} / \mathrm{s}$ in the absence of distraction, and $0.58 \mathrm{rads} / \mathrm{s}$ when either distraction task was used. 
Table 5. Analysis of Variance on the Effects of Age, Day, Speed Condition, and Distraction on Steering Deviations (in radians/second).

\begin{tabular}{|c|c|c|c|c|c|}
\hline \multirow[b]{2}{*}{ Effect } & \multicolumn{5}{|c|}{$\begin{array}{l}\text { Repeated Measures Analysis of Variance (avgwheelt } \\
\text { Sigma-restricted parameterization } \\
\text { Effective hypothesis decomposition }\end{array}$} \\
\hline & SS & \begin{tabular}{|c|} 
Degr. of \\
Freedom \\
\end{tabular} & MS & $F$ & $p$ \\
\hline Intercept & 540.3626 & 1 & 540.3626 & 2123.861 & 0.000000 \\
\hline Age & 3.7981 & 2 & 1.8990 & 7.464 & 0.002628 \\
\hline Error & 6.8695 & 27 & 0.2544 & & \\
\hline DAY & 1.1978 & 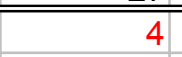 & 0.2994 & 4.918 & 0.001110 \\
\hline DAY*Age & 1.2256 & 8 & 0.1532 & 2.516 & 0.015083 \\
\hline Error & 6.5760 & 108 & 0.0609 & & \\
\hline SPEED & 6.6618 & 2 & 3.3309 & 147.854 & 0.000000 \\
\hline SPEED*Age & 0.4168 & 4 & 0.1042 & 4.625 & 0.002771 \\
\hline Error & 1.2165 & 54 & 0.0225 & & \\
\hline DISTRACT & 6.5419 & 2 & 3.2710 & 261.872 & 0.000000 \\
\hline DISTRACT*Age & 0.5543 & 4 & 0.1386 & 11.094 & 0.000001 \\
\hline Error & 0.6745 & 54 & 0.0125 & & \\
\hline DAY*SPEED & 0.2699 & 8 & 0.0337 & 1.850 & 0.069397 \\
\hline DAY*SPEED*Age & 0.8858 & 16 & 0.0554 & 3.035 & 0.000130 \\
\hline Error & 3.9402 & 216 & 0.0182 & & \\
\hline DAY*DISTRACT & 23.9343 & 8 & 2.9918 & 119.268 & 0.000000 \\
\hline DAY*DISTRACT*Age & 2.3987 & 16 & 0.1499 & 5.976 & 0.000000 \\
\hline Error & 5.4183 & 216 & 0.0251 & & \\
\hline SPEED*DISTRACT & 4 & 4 & 11.3469 & 677.609 & 0.000000 \\
\hline SPEED*DISTRACT*Age & 0.8836 & 8 & 0.1105 & 6.596 & 0.000001 \\
\hline Error & 1.8085 & 108 & 0.0167 & & \\
\hline DAY*SPEED*DISTRACT & 1117.5034 & $\mid \overline{16}$ & 7.3440 & 288.171 & 0.000000 \\
\hline $\mathrm{DAY}^{*}$ SPEED*DISTRACT*Age & 3.7110 & 32 & 0.1160 & 4.551 & 0.000000 \\
\hline Error & 11.0094 & 432 & 0.0255 & & \\
\hline
\end{tabular}

Figure 14 reflects the joint effects of speed and practice on the steering wheel deviations. The figure clearly reflects the improvement with practice and the consistently poorer performance at the higher required speed of $65 \mathrm{mph}$ than at the lower speed of $50 \mathrm{mph}$ and the car following mode. Practice and Speed interacted significantly with age, and the three-way interaction is depicted in figure 15. As can be seen from that figure, the most significant learning effect was observed for the older drivers. In fact, the steering deviations of the younger and middle age drivers, which were less than those of the older drivers, improved only slightly over the five days. In contrast, the older drivers started out with very high rate of deviations (in the $65 \mathrm{mph}$ and car-following condition) and improved consistently until, on Day 5, their performance was the same on all conditions, and similar to that of the younger drivers (except for the $50 \mathrm{mph}$ condition, where their performance remained poorer than that of the younger drivers). Thus, as with some of the 
measures before, the most significant learning is observed in the older drivers when driving under the most demanding conditions.

Figure 14. The Effects of Practice and Required Speed on the Drivers' Steering Wheel Deviations (in radians/second).

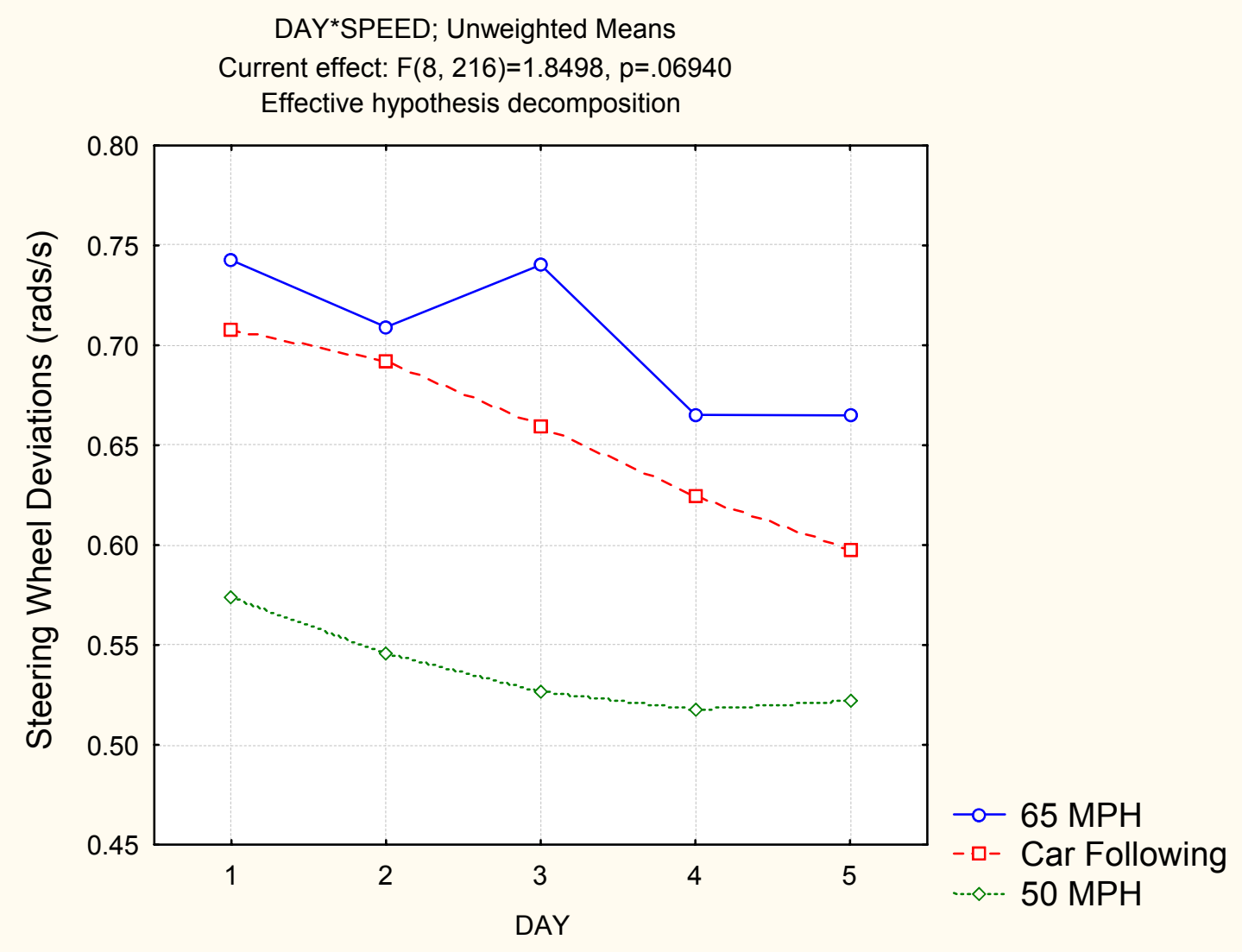


Figure 15. The Effects of Age, Practice and Required Speed on the Drivers' Steering Wheel Deviations (in radians/second).

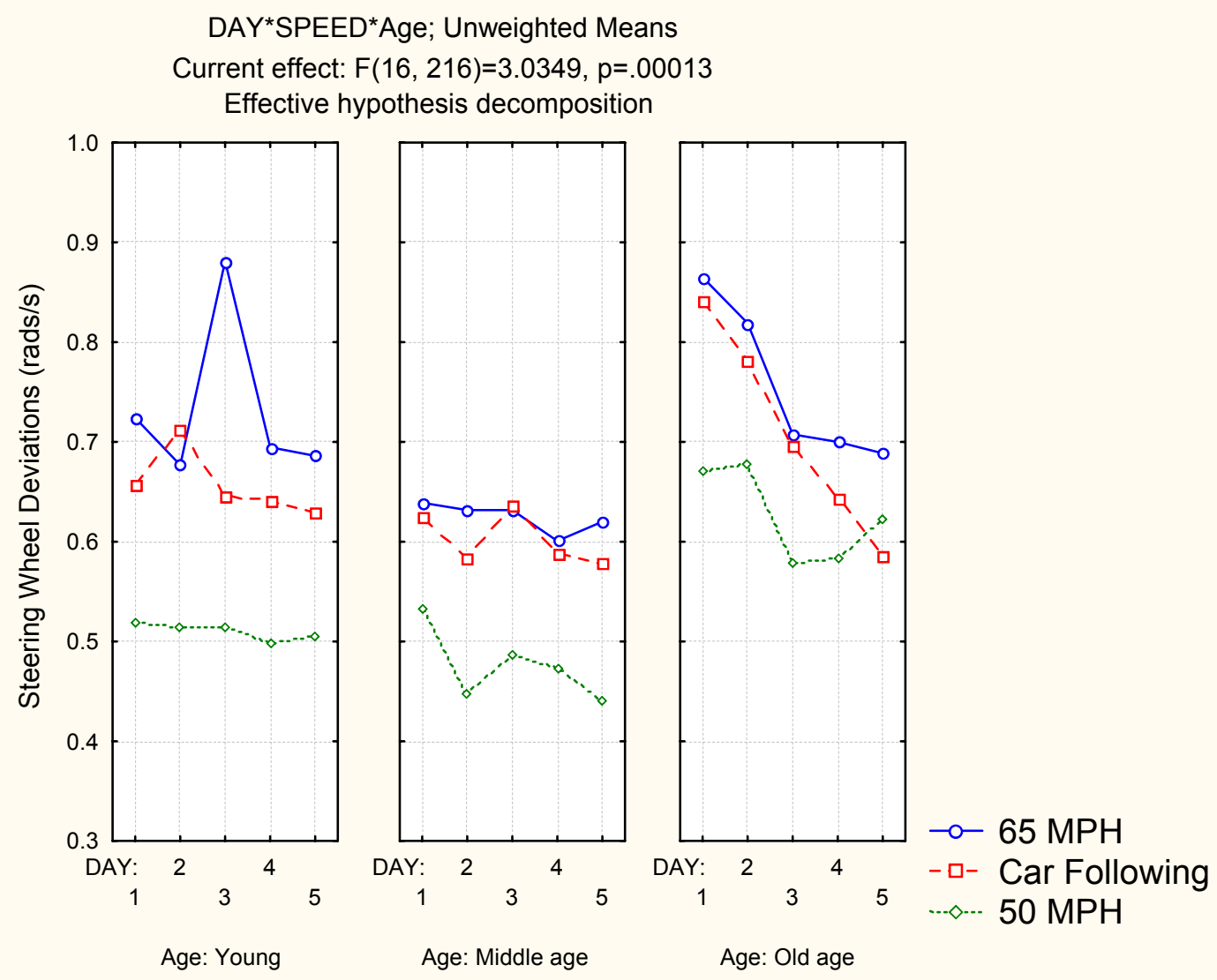

Distraction had a significant effect on steering wheel deviations both as a main effect and in its interactions with all of the other variables. However, the effects were either opposite than expected (more steering wheel deviations without distraction than with it), or complex. Figure 16 shows the 3-way interaction of distraction, practice and age on steering wheel deviations. No consistent pattern is apparent in the absence of distraction or when the distraction is limited to a conversation. However, the requirement to perform math operations yields a consistent pattern in which all drivers exhibit learning. More relevant to the central hypothesis of this study, is the fact that initially the older drivers' performance is significantly poorer than that of the two younger groups, but over time, with practice, all three groups converge so that on Day 5 their performance is essentially the same. The effect of practice on the older drivers is almost an inverse image of the effect of practice on the younger drivers. Since neither one shows a consistent trend, we have no explanation for this. 
Figure 16. The Effects of Age, Practice and Distraction on the Drivers' Steering Wheel Deviations (in radians/second).

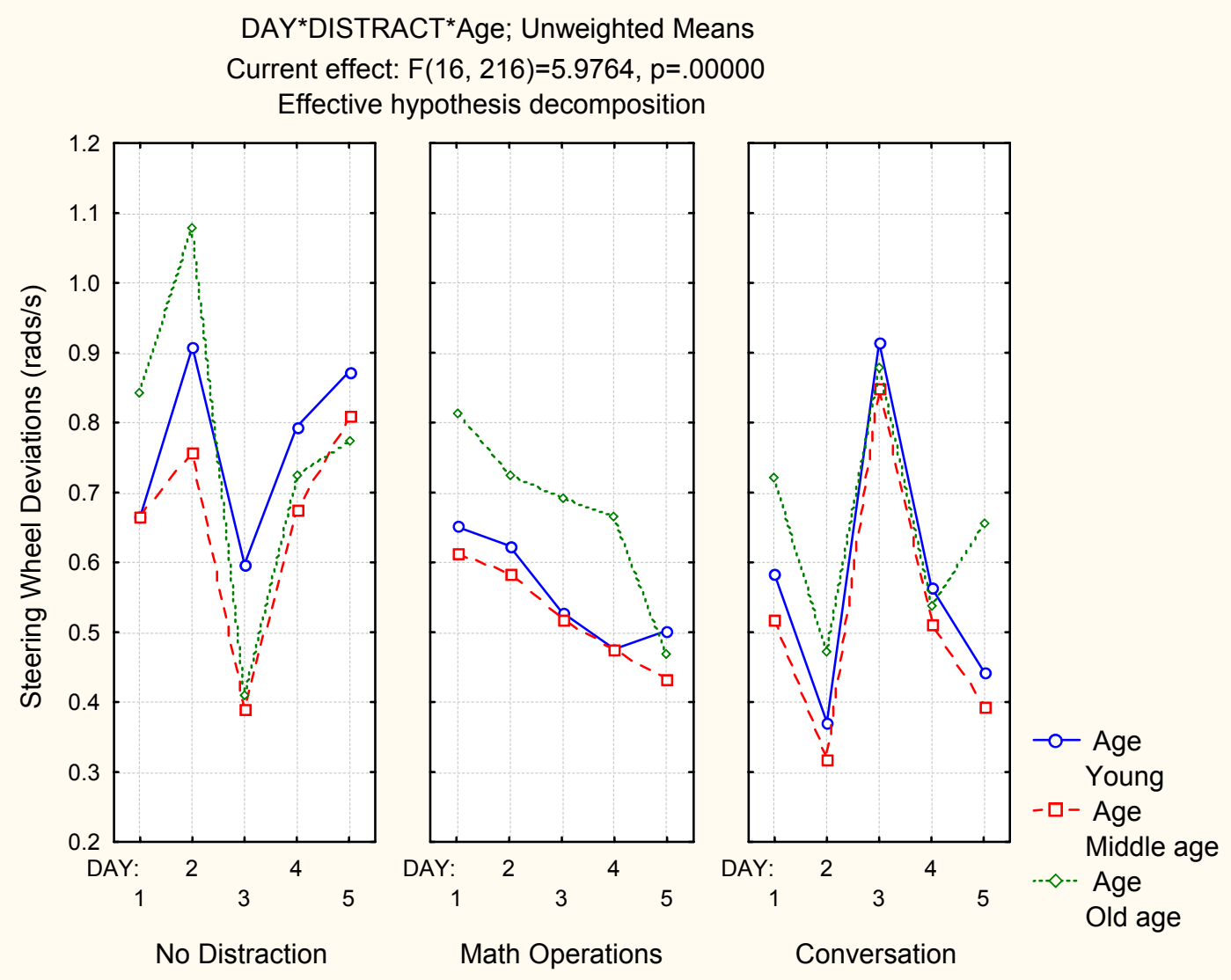

A detailed examination of the significant four-way interaction showed that the source of the consistent effect of the math operations was, as might have been expected, in the 65 mph condition. This is demonstrated in figures $17 \mathrm{a}$ and $17 \mathrm{~b}$, from which it can be seen that in this most demanding combination of speed and distraction there is a very consistent and large learning process in which drivers of all ages initially start out with deviations of 1.1-1.4 rads/s, and end up with nearly zero rads/s. Furthermore, initially there is a significant age effect where the older drivers are the poorest performers and the middle-aged ones are the best, and eventually all groups perform the same - with close to perfect performance. 
Figure 17a. The Effects of Age, Practice and Speed Condition on the Drivers' Steering Wheel Deviations (in rads/s), when Distracted by Requirement to Perform Math Operations.

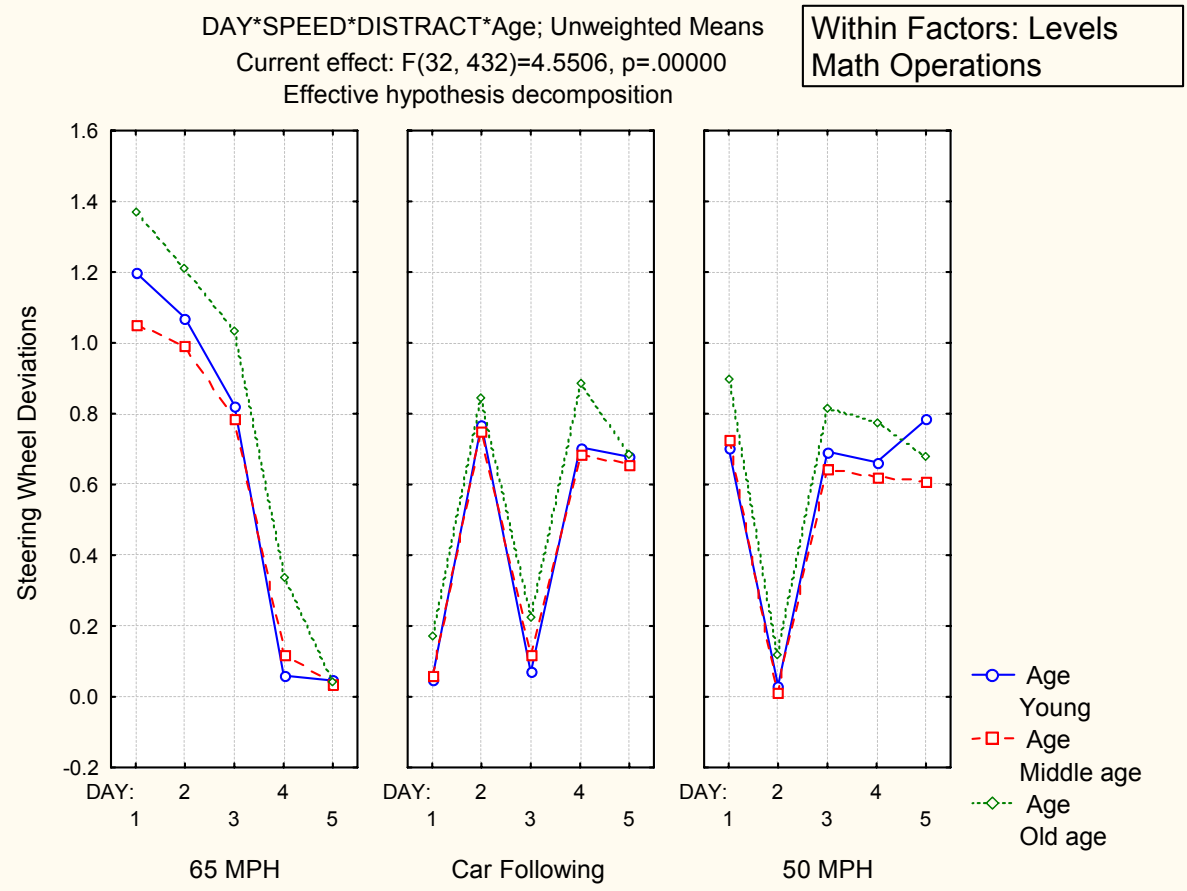

Figure 17b. The Effects of Age, Practice and Distraction on the Drivers' Steering Wheel Deviations (in rads/s), when Required to Maintain a Speed of $65 \mathrm{mph}$.

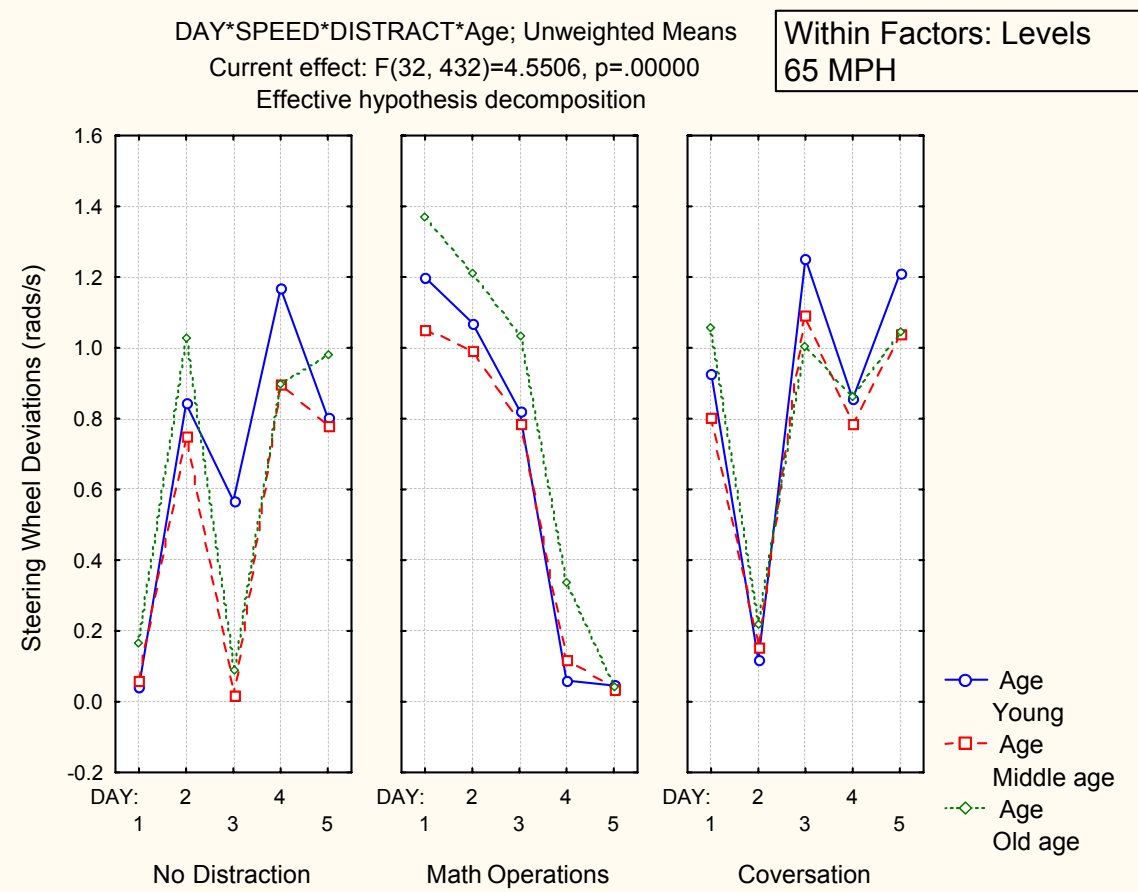




\section{Effects of Distraction on Crashes}

The number of crashes - including collisions and driving off the road - was very small: a total of 45 crashes for the 450 combinations of age $\mathrm{X}$ day $\mathrm{X}$ speed $\mathrm{X}$ distraction. With only $10 \%$ of the segments having crashes, it was impossible to analyze that data in a factorial design. Still, using Chi Square analysis it was possible to analyze the main effects. There were no consistent and significant effects of Day $(13,14,8,2$, and 8 crashes for Day 1 through 5), for age $(11,14$, and 20 crashes for young, middle-aged, and older drivers, and for Distraction $(13,16,16$ crashes for no distraction, math operations, and conversation). The only significant effect was obtained for speed, where the number of crashes was 26 for $65 \mathrm{mph}, 14$ for car following, and 5 for $50 \mathrm{mph}$ [Chi Square (2 df) $=7.99, \mathrm{p}=.01]$. This result also demonstrates the greater difficulty of driving at $65 \mathrm{mph}$ than car-following at a lower speed or driving at $50 \mathrm{mph}$.

\section{Effects of Distraction on Reaction Time to Peripheral Signals}

Reaction times (RT) to the peripheral signals were analyzed to a more limited extent because the signals appeared randomly during each session. Since there were 12 signals in each session and nine specific combinations of speed and distraction conditions, in some of the conditions no signals appeared at all. Consequently, because of these missing data, only main effects and two-way interactions could be analyzed.

The ANOVAs yielded a main effect of age $[\mathrm{F}(2,26)=20.75, \mathrm{p}<.0001]$, indicating longer reaction times for the older drivers $(2.38 \mathrm{~s})$ than for the middle age $(1.59 \mathrm{~s})$ or younger drivers (1.26s). Reaction times were also longer at the $65 \mathrm{mph}$ speed requirement (1.90s) than at the lower speeds (1.74s for the car-following, and $1.59 \mathrm{~s}$ for the $50 \mathrm{mph}$ ) $[\mathrm{F}(2,52)=5.37, \mathrm{p}=.008]$. The effect of practice was also significant $[\mathrm{F}(4,64)=4.87$, $\mathrm{p}=.002]$, with reaction time generally decreasing over the five days $(1.89 \mathrm{~s}, 1.65 \mathrm{~s}, 1.47 \mathrm{~s}$, $1.51 \mathrm{~s}$, and 1.32s on Days 1-5). Thus, as expected, reaction time increased with increasing difficulty of the driving task, increased with increasing driver age, and decreased with practice, indicating that whatever effects were observed in the driving measures they were not offset by a speed-accuracy effect in which drivers compensated for the poor driving by paying more attention to the peripheral signal reaction time task.

Interestingly, the effect of distraction was not significant either as a main effect, but was significant in its interaction with day, or practice $[\mathrm{F}(8,128)=2.77, \mathrm{p}=.0007]$. The interaction was due to the fact that on Days $1-3$, RT to the signals in the absence of any distraction was greater than with the distraction, and on Days 4-5, RT was faster without a distracting task than with it.

\section{Effects of Driving on Performance of Math Operations as a Distraction Task}


The best estimate of the effects of distraction on driving can be made when performance on the distraction task remains the same throughout all conditions. To that end participants were asked to be as accurate as possible on the math operations task under all driving conditions. Therefore, it is important to look not only at the effects of the distracting task on the driving, but also on the effects of the driving task on performance of the distracting task, with the hope of finding no significant effects. Nonetheless, performance on the math task also improved with practice. There were significant effects of Practice, age, and speed, and significant interactions of practice with both driver age and the required speed condition. These ANOVA effects are summarized in table 6. 
Table 6. Analysis of Variance on the Effects of Age, Day, and Speed Condition on Performance in the Distracting Math Operations Task.

\begin{tabular}{|l|r|r|r|r|c|}
\hline \multirow{4}{*}{ Effect } & \multicolumn{5}{|l|}{$\begin{array}{l}\text { Repeated Measures Analysis of Variance (matherror } \\
\text { Sigma-restricted parameterization } \\
\text { Effective hypothesis decomposition }\end{array}$} \\
\cline { 2 - 7 } & SS & $\begin{array}{c}\text { Degr. of } \\
\text { Freedom }\end{array}$ & MS & F & $p$ \\
\hline Intercept & 1365.902 & 1 & 1365.902 & 69.51200 & 0.000000 \\
\hline Age & 179.951 & 2 & 89.976 & 4.57894 & 0.019394 \\
\hline Error & 530.547 & 27 & 19.650 & & \\
\hline DAY & 120.787 & 4 & 30.197 & 20.16597 & 0.000000 \\
\hline DAY*Age & 58.427 & 8 & 7.303 & 4.87732 & 0.000037 \\
\hline Error & 161.720 & 108 & 1.497 & & \\
\hline SPEED & 21.338 & 2 & 10.669 & 9.65133 & 0.000261 \\
\hline SPEED*Age & 4.169 & 4 & 1.042 & 0.94282 & 0.446394 \\
\hline Error & 59.693 & 54 & 1.105 & & \\
\hline DAY*SPEED & 14.173 & 8 & 1.772 & 2.04598 & 0.042462 \\
\hline DAY*SPEED*Age & 16.253 & 16 & 1.016 & 1.17312 & 0.291369 \\
\hline Error & 187.040 & 216 & 0.866 & & \\
\hline
\end{tabular}

The effects of practice and age are illustrated in figure 18. As can be seen from this figure, in addition to the main effect of practice, drivers of all ages display a learning effect, but the learning gradient is much greater for the young novice drivers than for the older and middle-aged drivers (which, in turn, do not differ significantly from each other). The differences between the young drivers and the drivers belonging to the older groups persist only for the first two days, after which they are not statistically significantly different from each other. A similar pattern is observable for the interaction between practice and speed, which is reproduced in figure 19. The gradient of learning is greatest for the most demanding $65 \mathrm{mph}$ condition, which initially generates the most errors. However, by the third day the number of errors is essentially the same at all speed conditions, though the improvement in all speed conditions continues into Day 5. Taken together, these results suggest, that if anything, the learning effects, the greater difficulty experienced with the $65 \mathrm{mph}$, and the greater difficulty initially experienced by the young drivers as they were observed on the driving tasks are all probably an underestimate. No tradeoffs were observed between the driving tasks and the math operations task that would complicate the understanding of the results of the driving tasks, except for the fact that the continued reduction in errors on the math operations task beyond Day 3 is accompanied by an increase in the speed variance (figure 8), especially for the younger and older drivers on the difficult $65 \mathrm{mph}$ task (figure 9). 
Figure 18. The Effects of Age and Practice on the Number of Errors in the Distracting Math Operations Task.

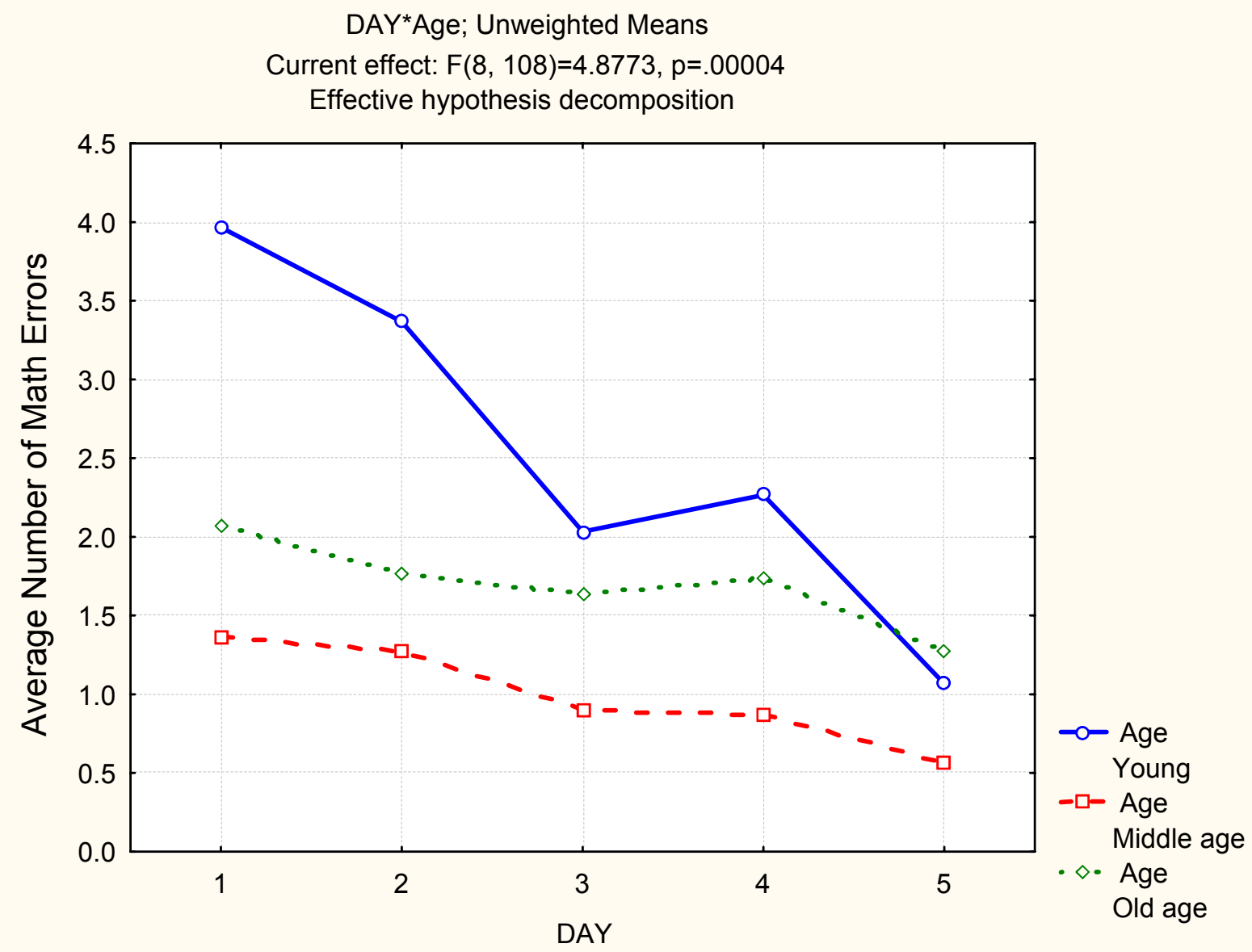


Figure 19. The Effects of Speed Condition and Practice on the Number of Errors in the Distracting Math Operations Task.

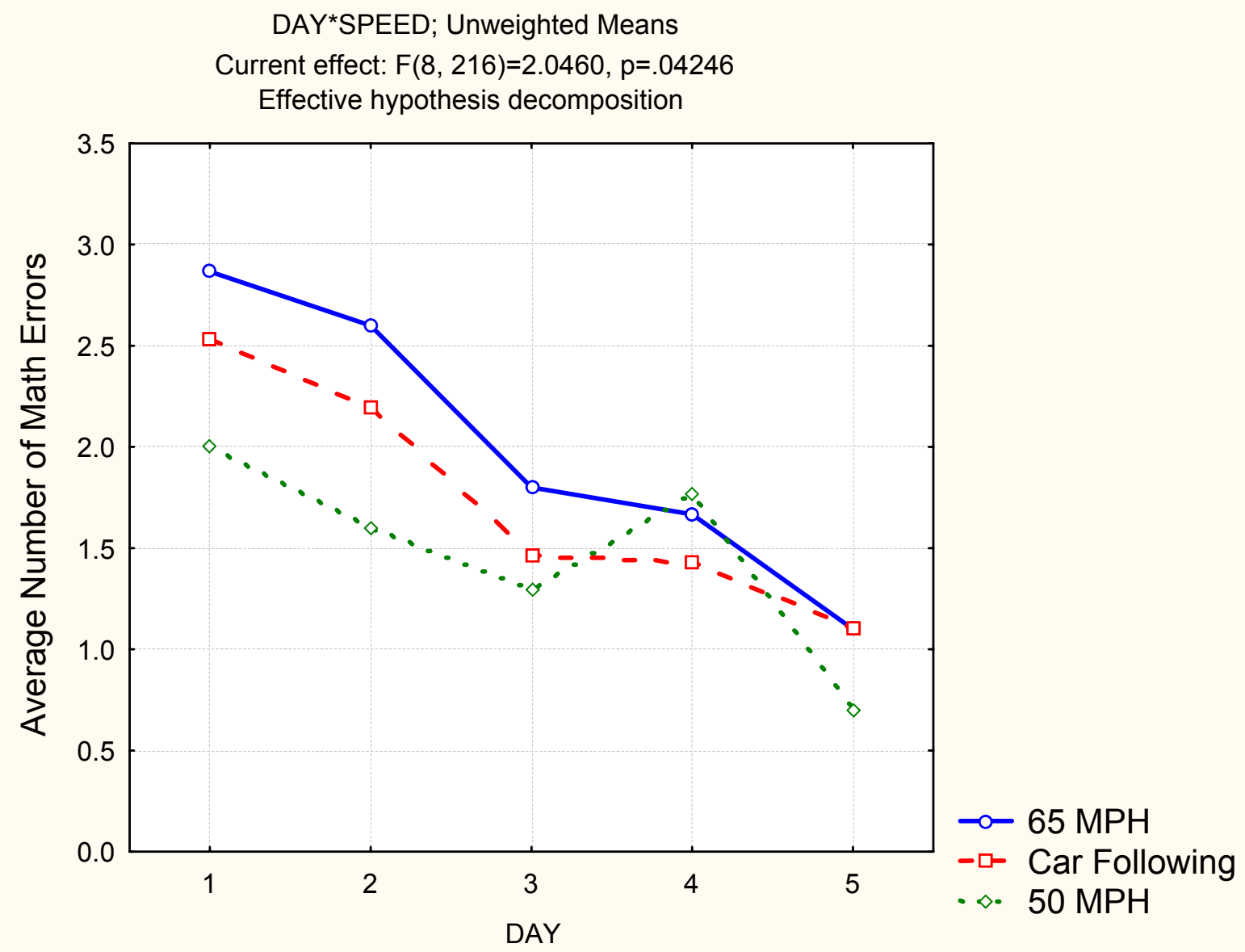

\section{Effects of Practice on the Subjective Estimates of Fatigue and Task Difficulty.}

As expected, the subjective evaluation of the workload and related measures decreased significantly over time. The participants rated their workload on a scale of 1 (very little) to 9 (very much) on six different dimensions. The results of the Analysis of Variance are presented in table 7. There was a significant main effect of a decrement in the effort experienced over the five days, and separate ANOVAs on each measure showed that the practice effect was significant for each of the six measures of workload. There was also a significant Days X Question interaction indicating that the rate of decrease was not the same for all measures. The rate of decrease in effort on each of the subjective measures is depicted in figure 20. The rate of decrease in workload was less for the question about the "physical demands" of the driving task than for all other measures, at least in part because on this measure even the initial rating was not very high. 
Table 7. Analysis of Variance on the Effects of Age, Day, Question on the Subjective Workload Assessment.

\begin{tabular}{|c|c|c|c|c|c|}
\hline \multirow[b]{2}{*}{ Effect } & \multicolumn{5}{|c|}{$\begin{array}{l}\text { Repeated Measures Analysis of Variance (Subjective } \\
\text { Sigma-restricted parameterization } \\
\text { Effective hypothesis decomposition }\end{array}$} \\
\hline & SS & \begin{tabular}{|c|} 
Degr. of \\
Freedom
\end{tabular} & MS & $\mathrm{F}$ & $p$ \\
\hline Intercept & 17680.13 & 1 & 17680.13 & 411.8766 & 0.000000 \\
\hline Age & 164.44 & 2 & 82.22 & 1.9153 & 0.166777 \\
\hline Error & 1159.00 & 27 & 42.93 & & \\
\hline DAY & 54542.76 & 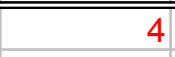 & 135.69 & 31.8033 & 0.000000 \\
\hline DAY*Age & 38.72 & 8 & 4.84 & 1.1344 & 0.346304 \\
\hline Error & 460.79 & 108 & 4.27 & & \\
\hline QUESTION & 238.58 & 5 & 477.72 & 17.5376 & 0.000000 \\
\hline QUESTION*Age & 26.75 & 10 & 2.68 & 0.9832 & 0.461062 \\
\hline Error & 367.30 & 135 & 2.72 & & \\
\hline DAY*QUESTION & 64.36 & 20 & 3.22 & 3.5048 & 0.000001 \\
\hline $\mathrm{DAY}^{*} \mathrm{QUESTION}{ }^{*} \mathrm{Age}$ & 34.36 & 40 & 0.86 & 0.9356 & 0.586085 \\
\hline Frror & 49581 & 540 & 092 & & \\
\hline
\end{tabular}


Figure 20. The Effects of Practice and Subjecive Workload Component on Subjective Workload Estimates*.

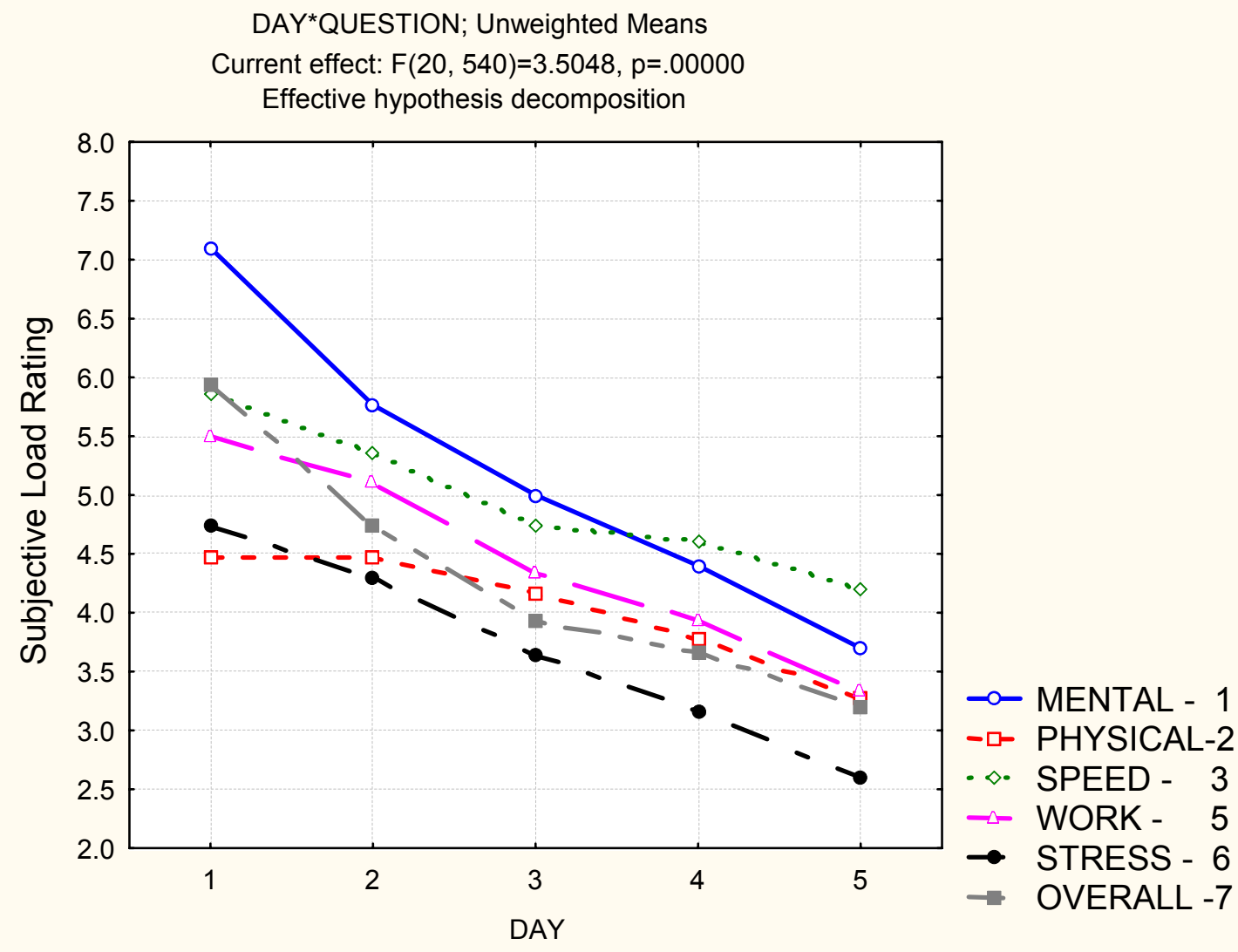

* Q4 is not included is this analysis since it was qualitatively different: asking the driver to evaluate his/her success in the task

The drivers' response to the question, "How successful were you at the driving task today?" showed no significant effect of day or age, but a marginally significant interaction of these two variables, $\mathrm{F}(8,108)=1.93, \mathrm{p}=.06$. This interaction is presented in figure 21 , from which it can be seen that while the drivers belonging to the youngest and oldest groups felt that their driving improved over time, the middle-aged drivers, if anything, felt that their driving actually deteriorated (however, the only significant contrast was between the youngest and middle-aged drivers on Day 5). 
Figure 21. The Effects of Practice and Age on Drivers' Estimates of How Well They Performed the Driving Task.

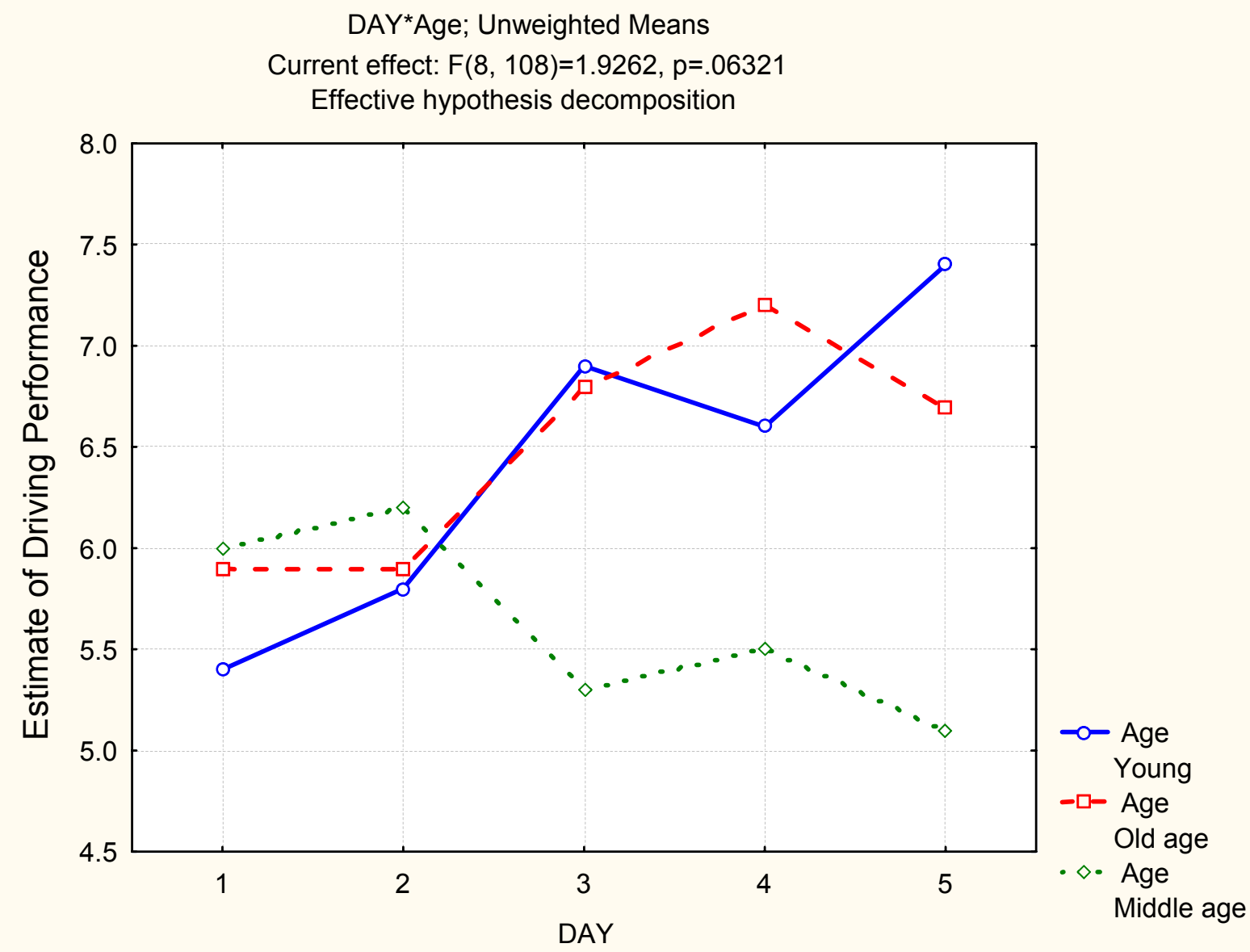




\section{SUMMARY OF RESULTS AND DISCUSSION}

The principal objective of this study was to assess the degree to which people can timeshare driving with a phone task when they are given time to practice both tasks. In general, the results demonstrated the existence of learning effects on most of the driving measures accompanied by reductions in the subjectively measured task load and task difficulty. Also, the results demonstrated that in the driving situations used - a monotonous road with a few turns and with little traffic - the effect of the distracting task - especially on the most demanding driving condition of maintaining a speed of $65 \mathrm{mph}$, and on the most vulnerable group of old drivers - diminished over time. Table 8 provides a summary of the principal findings relative to the effects of learning, the effects of the distraction, the interaction between the two main independent measures, and the association between these effects and age.

While the study findings do not point in a clear-cut direction, three relatively consistent findings that are critical to the validity of the study were apparent:

- The three required speed conditions were effective at differentiating the difficulty of the driving task. Performance on most measures was poorest when the drivers were required to maintain a constant speed of $65 \mathrm{mph}$, and best when the drivers were required to maintain a constant speed of $50 \mathrm{mph}$.

- The difficult phone task (math operations) did provide a significant distraction, as manifested in poorer performance on most of the driving measures. Performance was generally best without distraction and worst with the distracting math operations. The interference from the emotionally-involving conversation was moderate, and - depending on the specific measure of driving performance occasionally not even significant.

- Older drivers performed, in general and at least initially, worse than the two groups of younger drivers. However, they also improved more with practice until they sometimes reached the same level of performance as the younger drivers.

- The interference from the phone task on the driving task decreased with practice, and this was most apparent in the more demanding driving task (65 mph), and the more demanding interfering task (math operations).

There may be several reasons why the results presented above are difficult to present in the form of a simplistic conclusion. These include:

1. The use of multiple dependent measures that allow drivers to assume different strategic responses to the information overload.

2. The individual differences within each age group where different drivers have different information processing capacities.

3. The possible onset of boredom with a driving task that is repeated for five days, and the likelihood that such an effect would start at different times for different drivers.

All of these factors probably contributed to the significant amount of variance in the data, and occasionally to statistically significant effects for which we have no plausible interpretation. 
The results are also consistent with most of the previous research on the effects of distraction, since they clearly show a highly significant main effect of distraction on several of the driving measures (average speed, speed variance, and steering wheel deviations) and a marginally significant effect on the others (lane position and lane position variance). More important, in general, the effects of the distraction are most noticeable on Day 1. This is important because the results from Day 1 are the most comparable to the results of the previous studies that only employed one day (or one session) on which the effects were tested.

Table 8. Summary of the Effects of Practice and Distraction from Cell Phone Use on Driving Performance and Other Measures

\begin{tabular}{|c|c|c|c|c|}
\hline $\begin{array}{l}\text { Performance } \\
\text { Measure }\end{array}$ & $\begin{array}{l}\text { Learning/ } \\
\text { Practice } \\
\text { Effect }\end{array}$ & $\begin{array}{l}\text { Phone Distraction } \\
\text { Effect }\end{array}$ & $\begin{array}{l}\text { Practice } X \\
\text { Distraction } \\
\text { Interaction }\end{array}$ & $\begin{array}{l}\text { Age-Related } \\
\text { Interactions }\end{array}$ \\
\hline $\begin{array}{l}\text { Average } \\
\text { Speed }\end{array}$ & $\begin{array}{l}\text { Increases } \\
\text { for } 65 \mathrm{mph} \\
\text { requirement }\end{array}$ & $\begin{array}{l}\text { Significant for all } \\
\text { age groups but in } \\
\text { an inconsistent } \\
\text { manner }\end{array}$ & $\begin{array}{l}\text { Yes - at the } \\
\text { math task at } 65 \\
\text { mph, esp. for the } \\
\text { older drivers }\end{array}$ & $\begin{array}{l}\text { Most difficult } \\
\text { and greatest } \\
\text { learning effects } \\
\text { for older drivers }\end{array}$ \\
\hline $\begin{array}{l}\text { Speed } \\
\text { Variance }\end{array}$ & $\begin{array}{l}\text { Decreases, } \\
\text { esp. for } \\
\text { older drivers } \\
\text { and at } 65 \\
\text { mph }\end{array}$ & $\begin{array}{l}\text { Possibly but only } \\
\text { for math } \\
\text { operations, and not } \\
\text { for emotionally- } \\
\text { involving } \\
\text { conversation }\end{array}$ & $\begin{array}{l}\text { Not consistent, } \\
\text { but less on Day } 5 \\
\text { than Day } 1\end{array}$ & $\begin{array}{l}\text { Most difficult } \\
\text { and greatest } \\
\text { learning at } 65 \\
\text { mph, esp. for } \\
\text { older drivers }\end{array}$ \\
\hline $\begin{array}{l}\text { Average } \\
\text { Lane Position }\end{array}$ & $\begin{array}{l}\text { In car- } \\
\text { following, } \\
\text { and } 65 \mathrm{mph} \text {, } \\
\text { older and } \\
\text { middle age } \\
\text { drivers } \\
\text { move closer } \\
\text { to shoulder }\end{array}$ & $\begin{array}{l}\text { No significant } \\
\text { effect }\end{array}$ & $\begin{array}{l}\text { Significant but } \\
\text { inconsistent, } \\
\text { since effect of } \\
\text { distraction is } \\
\text { very small }\end{array}$ & $\begin{array}{l}\text { Oldest drivers } \\
\text { closest to center } \\
\text { of lane. } \\
\text { Youngest closest } \\
\text { to shoulder }\end{array}$ \\
\hline $\begin{array}{l}\text { Variance in } \\
\text { Lane Position }\end{array}$ & None & $\begin{array}{l}\text { None as main } \\
\text { effect }\end{array}$ & $\begin{array}{l}\text { Significant, } \\
\text { consistent } \\
\text { reduction with } \\
\text { math task at } 65 \\
\text { mph }\end{array}$ & $\begin{array}{l}\text { Variance } \\
\text { increased with } \\
\text { age }\end{array}$ \\
\hline $\begin{array}{l}\text { Steering } \\
\text { Deviations }\end{array}$ & Decreased & $\begin{array}{l}\text { Greater without } \\
\text { distraction than } \\
\text { with it }\end{array}$ & $\begin{array}{l}\text { Significant for } \\
\text { Math operations, } \\
\text { but not for } \\
\text { emotionally- } \\
\text { involving } \\
\text { conversation }\end{array}$ & $\begin{array}{l}\text { Greatest } \\
\text { reduction for } \\
\text { older drivers, at } \\
\text { end all ages are } \\
\text { the same }\end{array}$ \\
\hline
\end{tabular}




\begin{tabular}{|l|l|l|l|l|}
\hline $\begin{array}{l}\text { RT to } \\
\text { Peripheral } \\
\text { Signals }\end{array}$ & $\begin{array}{l}\text { RT } \\
\text { decreases } \\
\text { with } \\
\text { practice }\end{array}$ & None & $\begin{array}{l}\text { Significant but } \\
\text { not systematic } \\
\text { for any phone } \\
\text { task }\end{array}$ & $\begin{array}{l}\text { RT longer for } \\
\text { older drivers }\end{array}$ \\
\hline Crashes & $\begin{array}{l}\text { Insufficient } \\
\text { data }\end{array}$ & Insufficient data & Insufficient data & Insufficient data \\
\hline $\begin{array}{l}\text { Math } \\
\text { Operations }\end{array}$ & $\begin{array}{l}\text { Errors } \\
\text { decreased, } \\
\text { especially } \\
\text { for young } \\
\text { drivers, and } \\
\text { at } 65 \text { mph }\end{array}$ & Not relevant & Not relevant & $\begin{array}{l}\text { Older drivers } \\
\text { initially better } \\
\text { than young } \\
\text { drivers and have } \\
\text { less room to } \\
\text { improve }\end{array}$ \\
\hline $\begin{array}{l}\text { Subjective } \\
\text { Workload }\end{array}$ & $\begin{array}{l}\text { Decreased } \\
\text { on all } \\
\text { measures }\end{array}$ & Not relevant & Not relevant & $\begin{array}{l}\text { No age-based } \\
\text { differences }\end{array}$ \\
\hline
\end{tabular}

In addition, the inclusion of the more difficult $65 \mathrm{mph}$ requirement and the inclusion of older drivers (both of which were not present in our first study), yielded the learning effects that we sought for most of the measures. This enabled us to test the main hypothesis that with practice, performance on the driving task should improve, and the difference in driving performance with and without distraction should diminish. Consequently, it was in the more demanding situations and for the initially less able drivers (older drivers), that the greatest learning effects were observed, whereby the effects of the interfering task on the driving task diminished over time.

The results of this study also demonstrated another phenomenon that is consistent with the active nature of the driving task: that drivers can, and sometimes do, adjust their behavior to compensate for information overload. In the present study this was apparent in the driving speed, especially in the high-speed requirement. In the $50 \mathrm{mph}$ and in the car-following condition, the demands were not that high, so drivers achieved the desired speed already on the first session and maintained it throughout the five days. In contrast, in the $65 \mathrm{mph}$ condition, there was a typical logarithmic learning curve, and even on the last day the drivers still drove below the desired $65 \mathrm{mph}$.

The nature of the distracting task is very critical to any evaluation of its effects on driving. This is because theoretically at least, the more demanding the cognitive aspect of the subsidiary task, the more it should interfere with the driving task. For this reason in order to evaluate the impact of a phone conversation on the driving task and driving safety, it is very important that the distracting task resemble in its demands the demands placed on the driver by a real phone conversation. Unfortunately many of the studies on the effects of cell phone use on driving used tasks such as "shadowing" (Strayer and Johnston, 2001), math operations (Harbluk, Noy, and Eizenman, 2002; McKnight and McKnight, 1993; Parkes and Hooijmeijer, 2001), memory tasks (Alm and Nilsson, 1995), and reasoning operations (Haigney, Taylor, and Westerman, 2000; Parkes and Hooijmeijer, 2001; Strayer and Johnston, 2001) to simulate the phone conversation. Whether or not these tasks are more demanding, less demanding, equally demanding, or 
task cognitive functions that are different from most phone conversations is often unknown.

In the few studies where simulated conversations were compared to other tasks, the conversation was either significantly less distracting than mathematical operations (e.g. McKnight and McKnight, 1993), or not measurably distracting at all (Briem and Hedman, 1995). One difficulty of simulating a true phone conversation is that it cannot be standardized across subjects and even kept constant in its cognitive demands across time within subjects. This is because every conversation is unique in its effects on the different participants, and drivers always have the option of pacing their responses to accommodate the driving requirements. Briem and Hedman (1995) who failed to find driving impairment due to conversation on the phone concluded that "the use of a handsfree telephone does not in itself increase the risk of an incident... while simple manipulation-free conversation may, actually, contribute to a decrease in the deviation from the correct path." The problem is further exacerbated when distraction tasks are labeled as "conversations" even though they are not. For example, McKnight and McKnight (1993) called their math operations task "intense conversation" as distinct from a "casual conversation" that consisted of asking the drivers what they "did for a living, what they did with their free time, etc." Then when math operations were determined to be significantly more distracting than the "casual conversation", the authors concluded that "intense conversations provided the greatest overall degree of performance decrement," when in fact no intense conversations were conducted at all. Similarly, Strayer and Johnston's (2001) “conversing” task was a complex shadowing task where the participants heard words, and in response to each word they had to generate a different word beginning with the last letter of the word they just heard. Yet, the title of Strayer and Johnston's paper referred to "conversing on a cellular phone." Further distortion of the findings was made when this terminology was adopted verbatim by the press.

As with the phone conversation, so often the driving task used in experimental studies is at best a very partial simulation of actual driving. For example, Irwin, Fitzgerald, and Berg (2000), measured foot reaction time to a light in the presence of different phone tasks - presumably conversations with varying amounts of cognitive or emotional stress and titled their study "Effect of the intensity of wireless telephone conversations on reaction time in a braking response." In fact, their study had no elements of driving at all (not even braking) other than a reaction time task. Strayer, and Johnston (2001), used a pursuit tracking task and titled their study as "Driven to Distraction: Dual-Task Studies of Simulated Driving and Conversing on a Cellular Phone." Interestingly, in the first of two studies that they conducted they complicated their "driving" task by having the driver also respond whenever the target "flashed" red or green. However in the second study, in which the detrimental effect of the "conversation" was noted, they omitted the color change because it added "substantial noise in the tracking data." Thus when the option to add some of the complexities of driving was considered, it was rejected in favor of using a simpler task. 
The design of the present study was based on a relatively high-fidelity driving simulator (though still fixed-base with a single $40^{\circ}$ field of view screen), and compared the effects of distraction from math operations with the effects of distraction from a presumably demanding conversation that challenged the drivers' belief systems and self perceptions. As in the previous studies quoted above, the conversation - even though it was emotionally engaging - turned out to be much less demanding than the math operations. Perhaps one reason for the difference is that the conversation - at least in part - can be paced by the driver while the math operations (as most of the other distracting tasks used in other studies) are experimenter-paced and thus can be much more demanding vis-à-vis the time-sharing requirements.

Finally, it is of interest to note that the car-following task was less affected by the phone task, than the requirement to keep a constant and high speed. It implies that as long as the driver is not required to keep a fixed distance-headway or time-headway, simply driving behind another car that changes its speed from time to time can be safely accomplished while performing a secondary task such as a phone conversation. However, in our study, the lead car never stopped abruptly and so the driver's readiness to respond to a sudden change was never tested. 


\section{CONCLUSIONS}

The effects of conversing on the phone while driving are not simple, static, or uniform. This is true for different driving conditions, different phone tasks, different driving tasks, and different people. Despite the complexity of the results, the following general conclusions can be made regarding the driving conditions and tasks examined in this study:

- There is a learning process that occurs for both the driving task and the distraction task. Over the course of five sessions there was an improvement in the performance of most of the driving measures and on the math distraction task. In parallel, the subjectively evaluated workload decreased in a fairly monotonic manner.

- Performance, in general, is poorest for the older drivers, and better for the two younger groups of drivers, which generally do not differ from each other.

- Performance on the driving task is significantly affected by the required speed, being generally poorer when required to drive at $65 \mathrm{mph}$ than when required to drive at $50 \mathrm{mph}$ or follow another vehicle (also at speeds less than $65 \mathrm{mph}$ ).

- Of the two phone distracting tasks used, the math operation is a much more difficult task, as reflected in the poorer performance on the driving measures.

- An emotionally-involving conversation is much less disruptive to driving than a math operation, and in the case of many driving measures, it appears to be nondisruptive at all (relative to the no distraction condition).

- The significant interaction of the above conditions shows that the effects of the distracting task on driving are greatest when the distracting task is difficult (math operations), the driving demands are high $(65 \mathrm{mph})$, the driver has no experience in performing the dual tasks (Day 1), and the drivers are older (60-71 years old).

- Consequently, in accordance with the main hypothesis of this study, where learning is observed, practice diminishes or completely eliminates the differences in the performance on the driving task, between the no-distraction condition and the two phone distraction conditions. 


\section{REFERENCES}

Alm, H., \& Nilsson, L. (1993). Changes in driver behavior as a function of a hands-free mobile telephones. Accident Analysis and Prevention, 26, 441-451.

Briem, V., and Hedman, L.R. (1995). Behavioral effects of mobile telephone use during simulated driving. Ergonomics, 38(12), 2536-2562

Brookhuis, K. A., de Vries, G., \& de Waard, D. (1991). The effects of mobile telephoning on driving performance. Accident Analysis and Prevention, 23 (4), 309-316.

Brown, I.D., Tickner, A.H., and Simmonds, D.C. (1969). Interference between concurrent tasks of driving and telephoning. Journal of Applied Psychology, 53 (5), 419-424.

Drory, A. (1985). Effects of rest and secondary task on simulated truck-driving task performance. Human Factors, 27(2), pp. 201-207.

Fuller, R.G.C. (1984). Prolonged driving in convoy: The truck driver's experience. Accident Analysis and Prevention, 16, 371-382.

Goodman, M. (1997). An Investigation of the Safety Implications of Wireless Communications in Vehicles. NHTSA Report No. DOT HS 808 635, U.S. Department of Transportation, Washington D.C.

Goodman, M.J., Tijerina, L., and Bents, F. (1999). Wireless communications from vehicles: Safe or unsafe? Transportation Human Factors Journal, 1 (1), 3-42

Hahn, R.W., and Dudley, P.M. (2002). The Disconnect Between Law and Policy Analysis: A Case Study of Drivers and Cell Phones (Working Paper 02-7). Washington, DC: The AEI-Brookings Joint Center for Regulatory Studies.

Haigney, D.E.; Taylor R.G. \& Westerman, S.J. (2000). Concurrent mobile phone use and driving performance. Transportation research, part F, 3, 113-121.

Hancock, P.A., Lesch, M., and Simmons, L. (2003). The distraction effects of phone use during a crucial driving maneuver. Accident Analysis and Prevention, in press.

Harbluk, J.L., Noy, Y.I., and Eizenman, M. (2002). The Impact of Cognitive Distraction on Driver Visual Behaviour and Vehicle Control (TP\# 13889 E). Transport Canada.

Irwin, M., Fitzgerald, C., and Berg, W.P. (2000). Effect of the intensity of wireless telephone conversations on reaction time in a braking response. Perceptual \& Motor Skills, 90, 1130-1134.

Ishida, T., and Matsuura, T. (2001). The effect of cellular phone use on driving performance. IATSS Research, 25(2), 6-14. 
Laberge-Nadeau, C., Maag, U., Bellavance, F., Desjardins, D., Messier, S., and Saïdi, A. (2001). Wireless telephones and the risk of road accidents (Final report, CRT-2001-16). Montréal, Canada: Laboratoire sur la sécurité des transports, Université de Montréal.

Lissy, K.S., Cohen J.T., Park M.Y., and Graham J.D. (2000). Cellular Phone Use While Driving: Risks and Benefits. Boston, MA: Harvard Center for Risk Analysis.

McKnight, A.J., and McKnight, A.S. (1991). The effect of cellular phone use upon driver attention. AAA Foundation for Traffic Safety Report.

McKnight, A.J. and McKnight, A. S. (1993). The effect of cellular phone use upon driver attention. Accident Analysis \& Prevention, Vol. 25 (3), 259-265.

Mourant R. and Rockwell, T.H. (1972). Strategies of visual search by novice and experience drivers. Human Factors, 14, 325-335.

Oron, T., Ronen, A., Shinar, D. and Cassuto, Y. (2002). The effects of alertness maintaining tasks on driver fatigue. Proceedings of the Human Factors and Ergonomics $\underline{\text { Society } 46^{\text {th }}}$ Annual Meeting, Baltimore, MD, October, 1-4.

Parkes, A.M., and Hooijmeijer, V. (2001). Driver Situation Awareness and Carphone Use. Transport Research Laboratory. Crowthorne, England.

Redelmeier, D.A. \& Tibshirani, R.J. (1997). Association between cellular telephones calls and motor vehicle collisions. The New England Journal of Medicine, Vol. 336 (2), 453-458.

Royal, D. (2003). National Survey of Distracted and Drowsy Driving. National Highway Traffic Safety Administration, Report No. DOT HS 809 566. U.S. Department of Transportation, Washington, D.C.

Shinar, D., Meir, M., and Ben-Shoham, I. (1998). How automatic is manual gear shifting? Human Factors, 40, 647-654.

Shinar, D., Tractinsky, N., and Compton, R.C. (2002). Practice with a cell-phone task in simulated driving. Proceedings of the 2002 Transportation Research Board Annual Conference, Washington, D.C., January.

StatSoft Inc. (2001). Statistica (Data Analysis Software System) Version 6.0. http://www.statsoft.com.

Strayer, D.L., and Johnston, W.A. (2001). Driven to distraction: Dual-task studies of simulated driving and conversing on a cellular phone. Psychological Science, 12 (6), 462-466. 
Utter, D. (2001). Passenger Vehicle Driver Cell Phone Use: Results from the Fall 2000 National Occupant Protection Use Survey. NHTSA Research Note. DOT HS 809293. U.S. Department of Transportation, Washington, D.C.

Waugh, J.D., Glumm, M.M., Kilduff, P.W., Tauson, R.A., Smyth, C.C., and Pillalamarri, R.S. (2000). Cognitive workload while driving and talking on a cellular phone or to a passenger. Proceedings of the $44^{\text {th }}$ Annual Meeting of the Human Factors and Ergonomics Society. San Diego, CA, July-August.

Wickens, C.D. and Hollands, J.C. (1999). Engineering Psychology and Human Performance. New York: Prentice-Hall. 


DOT HS 809826

December 2004

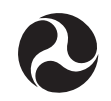

U.S. Department

of Transportation

National Highway

Traffic Safety

Administration

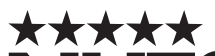

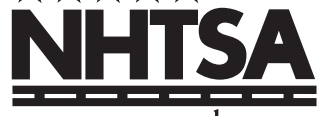

www.nhtsa.gov 